\title{
تحديد أنسب المعايير البنائية لتقدير جودة الخواص الحرارية للملابس الخارجية الفضفاضة
}

\author{
إعداد \\ م/ جيهاب محمود عبد الحميد \\ مدرس النسيج والملابس - قسم الاقتصاد المنزلي - ماليل \\ كلية التربية النوعية - جامعة المنصورة
}

مجلة بحوث التربية النوعية ـ جامعة المنصورة

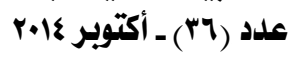




\title{
تصديد أنسب المعايير البنائية لتقدير جودة الخواص الحرارية \\ للمبلابس الخارجية الفضفاضة
}

\author{
إعداد \\ */جيهانمحمد عبد الحميد
}

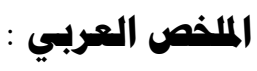

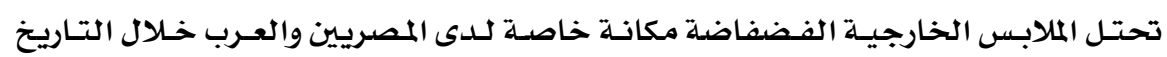

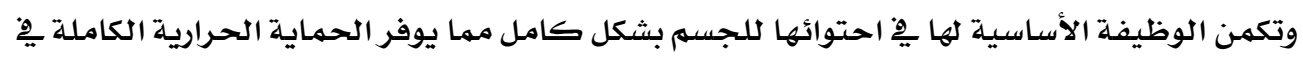

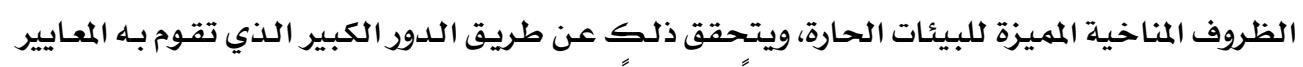

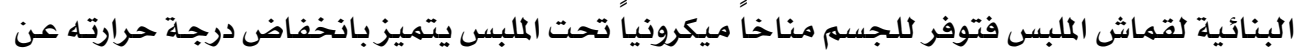
الوسط المحيط.

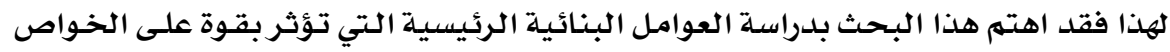

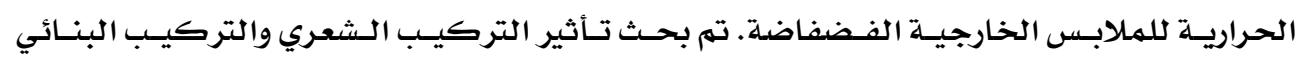

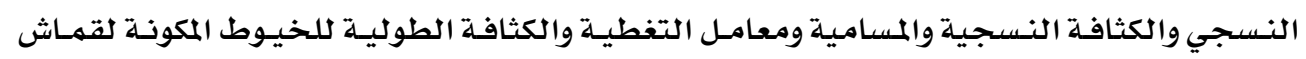

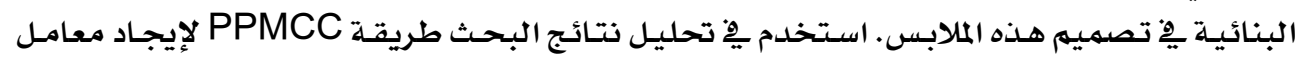

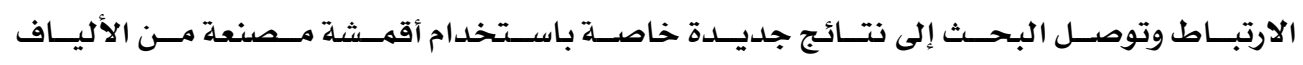
الصناعية والمخلوطة.

هقدمة البحث:

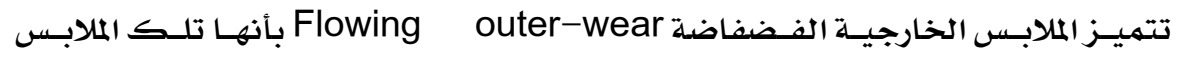

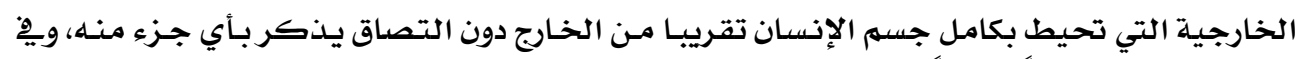

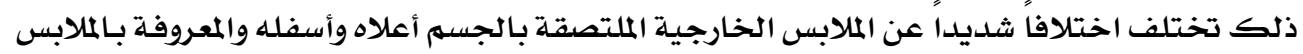

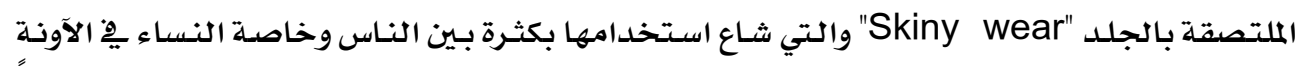

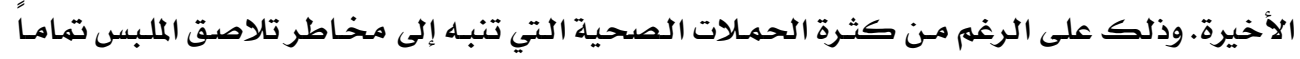

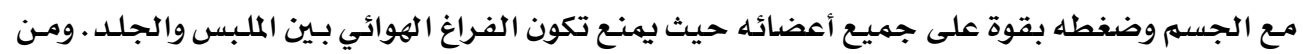

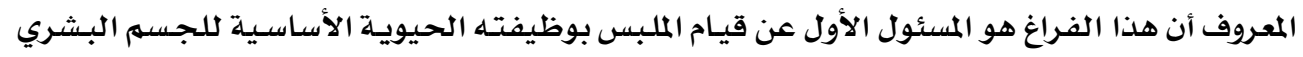

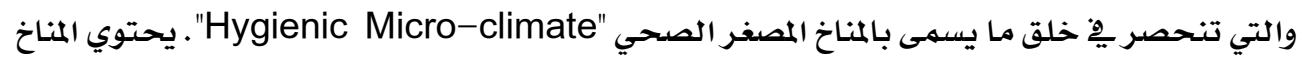

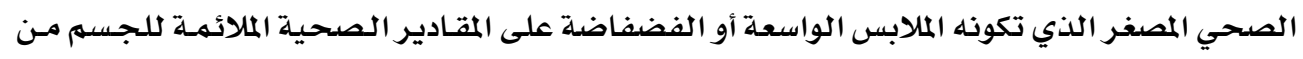

* مدرس النسيج والملابس - قسم الاقتصاد المنزلي - كلية التربية النوعية - جامعة المنصورة 
جميع عناصر المناخ العادي. وتتحدد قيم هذه المقادير المناخية الصحية ويقدرة مهارة مصمهم الملبس يف تصميهمه الكامل لله(17).

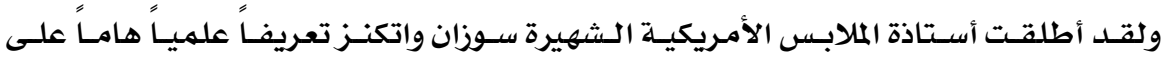

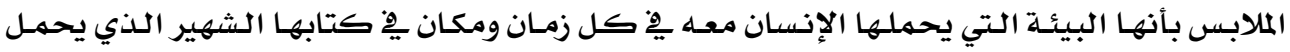

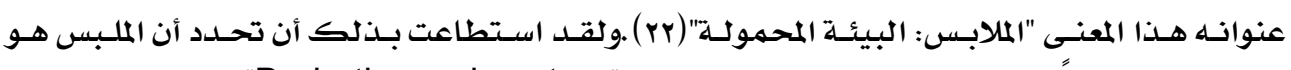

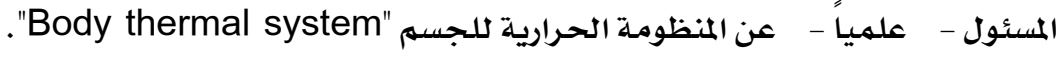

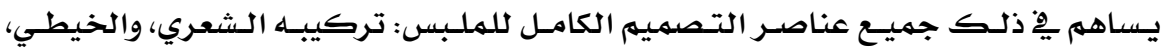

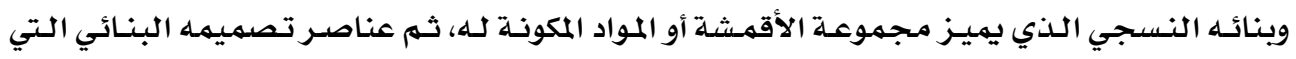

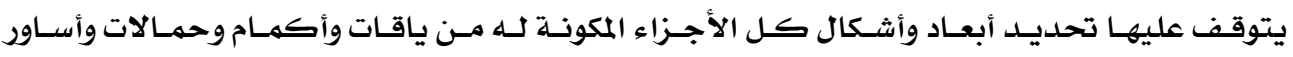

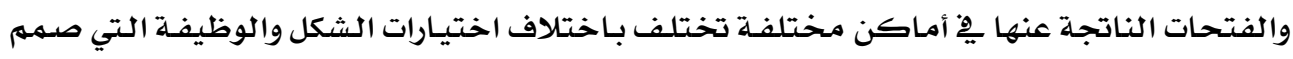
الملبس من أجلها.

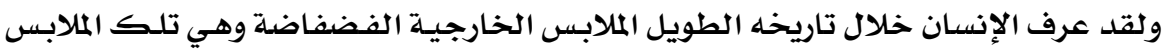

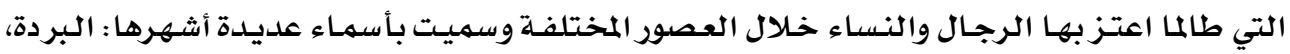

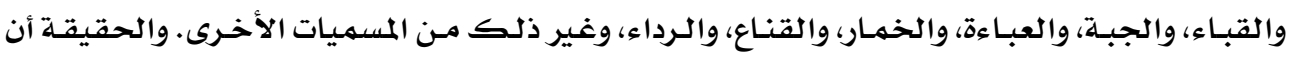

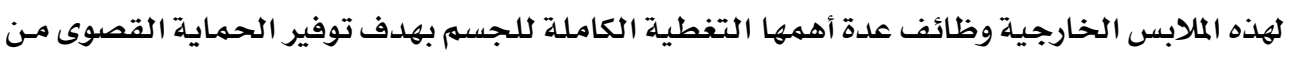

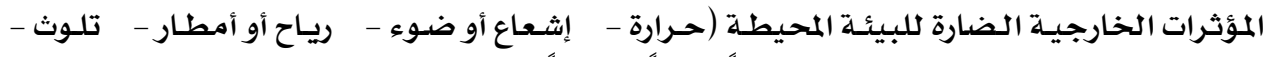

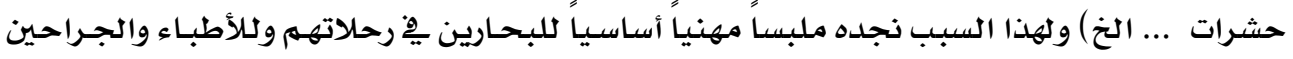

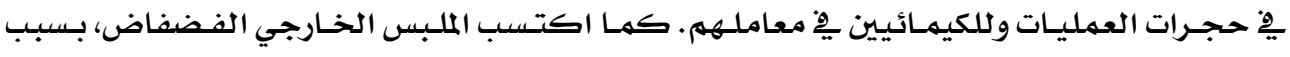

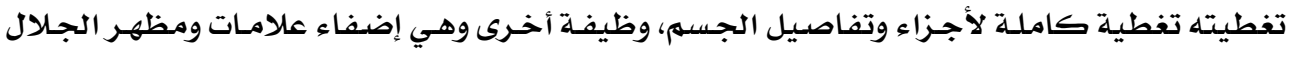

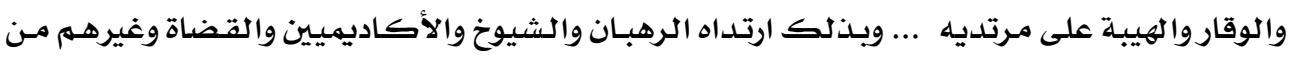

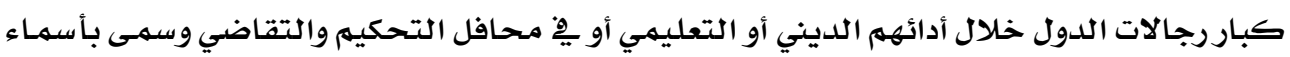
مختلفة كالبردات والأرواب والقباء ... الخ (ع ). وبصرف النظر عن وظيفة الحماية ووظيفة الهيبـة والوقار (الاجتماعيـة) للملبس الخـارجي

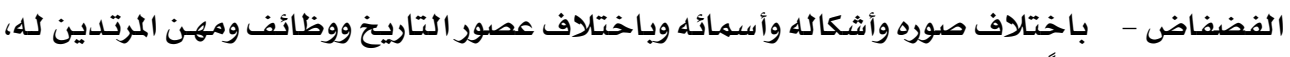
فقد اكتسب أيضاً وظيفة جمالية.

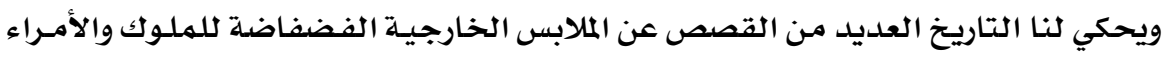

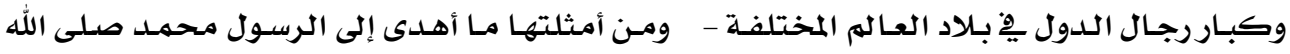

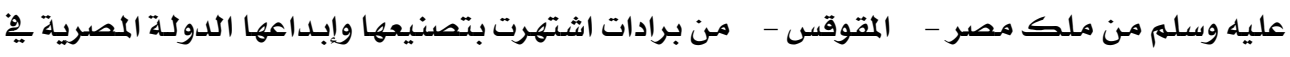

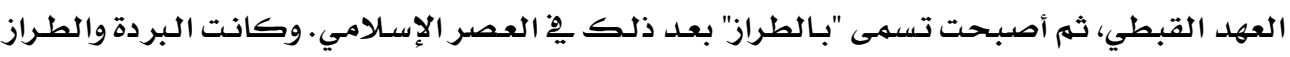

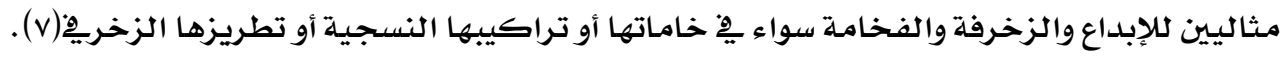

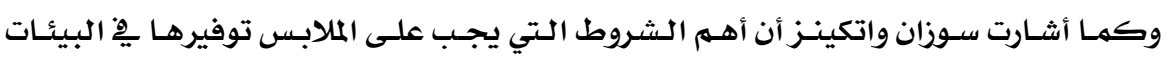

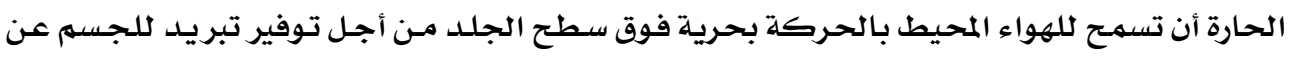


$+$

طريـق تيـارات الحمـل وبخـر العـرق، كهـا يجـب أيضضا على التصميهم الملبسـي أن يتميـز بإتاحسة حريسة

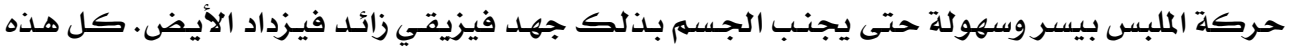

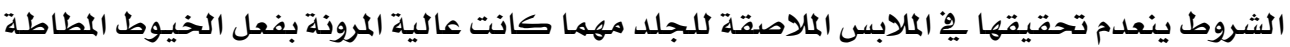

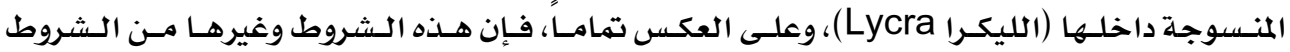

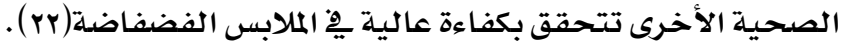

\section{هشكلة البحث: مشئ}

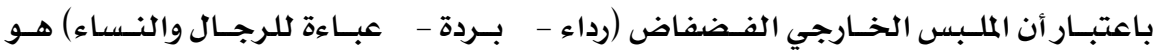

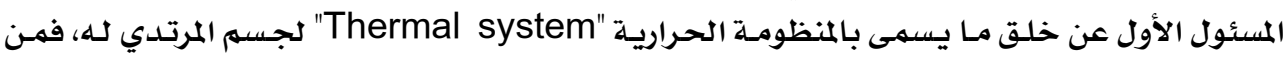

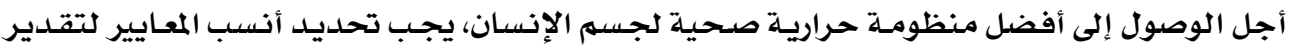

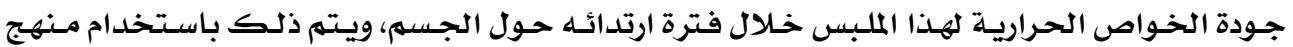
تجريبي يتوصل إلى تحديد أفضل العوامل البنائية النسجية للملابس الخارجية الفضفاضية.

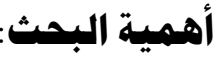

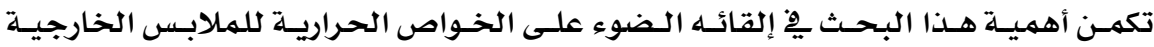

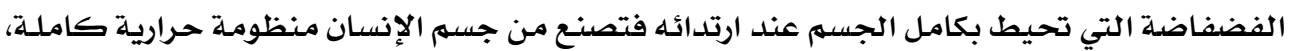

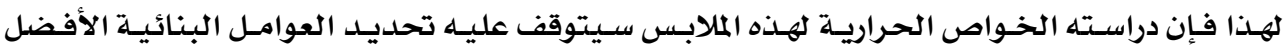
لخامة الملبس وتركيبها النسجي الذي يحقق للجسم أفضل منظومة حرارية صحرية لهية له أثناء الارتداء.

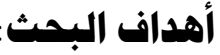

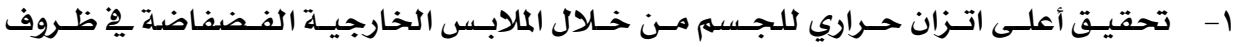
مناخية محددة.

ب- إلقاء الضوء على الأهمية العلمية والتصميمية للخواص الحرارية للملابس الخارجية بشكل

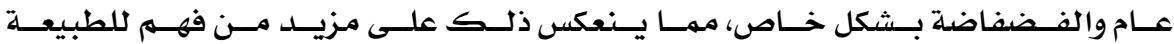
الاستخدامية للمملابس.

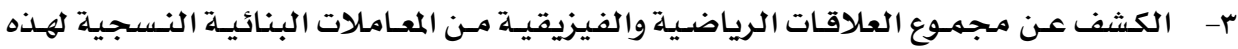
الملابس وبين خواصها الحراريـة المختلفة. تنحصر الفروض الأساسية لهذا البحث فيما يأتي: 1- يؤثر سمك قماش الملبس الخارجي الفضفاض تأثيراً كبيراً على خواصده الحرارية المختلفة.

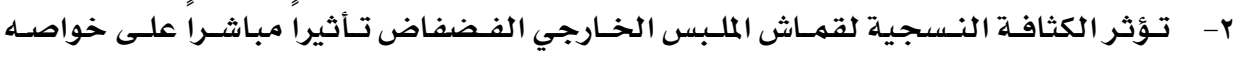

الحرارية المختلفة.

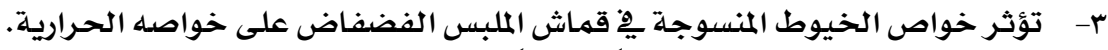

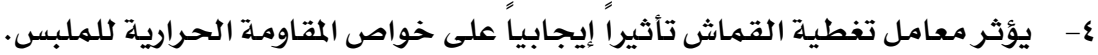


ه- يؤثر التركيب النسجي للأقمشة تأثيراً كبيراً على خواصها الحرارية.

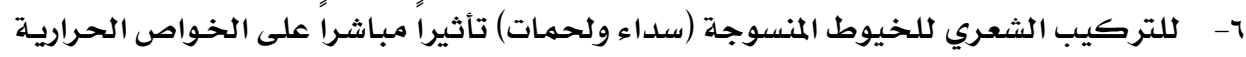

للمسلبس الخارجي.

هدود البحث:

1- الظروف المناخية: البيئات الحارة ممثلة يِّا البيئة الحارة المصرية.

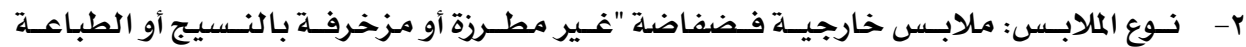

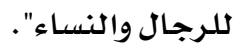

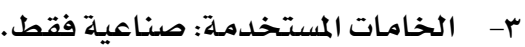

هنهمبية البحث

المنهج التجريبي والمنهج التحليلي.

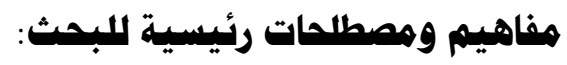

اـ الخواص الحرارية للملبس

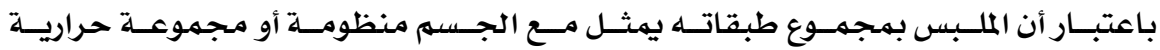

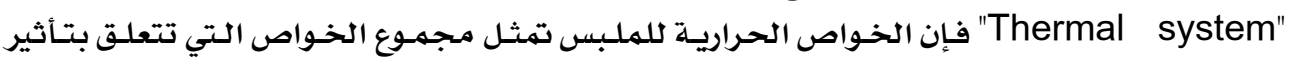

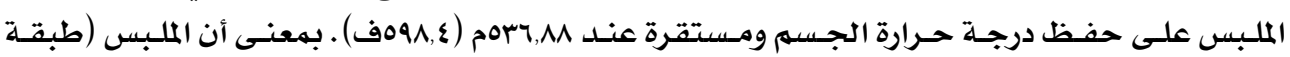

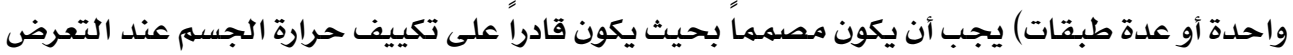
للظروف الحرارية المختلفة للبيئة المحيطة (ه) ).

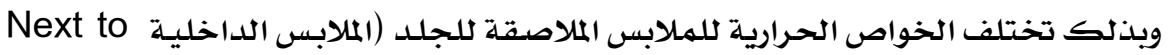

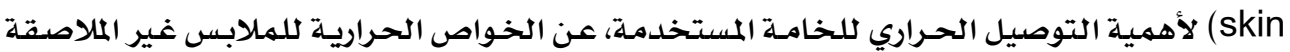

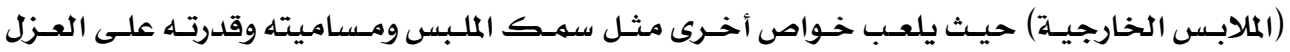

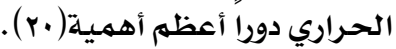

بـ البيئات الحارة مثثلة في البيئة الحارة المصرية: Hot Climatic Environment

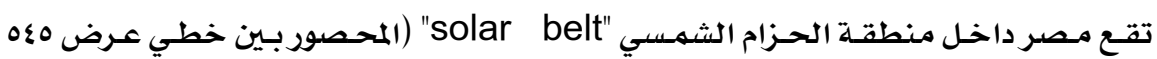

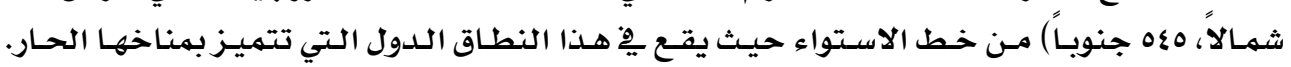

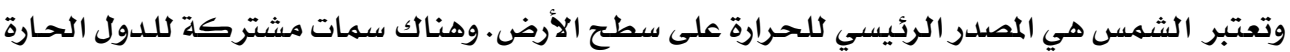

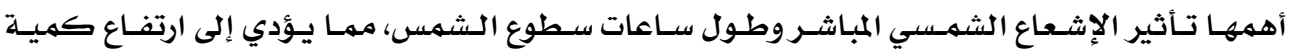

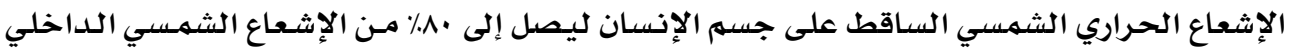

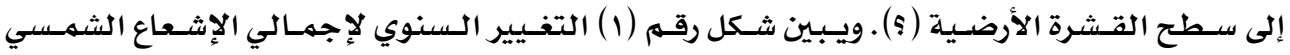

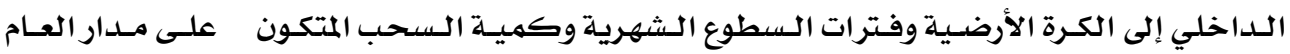
. 


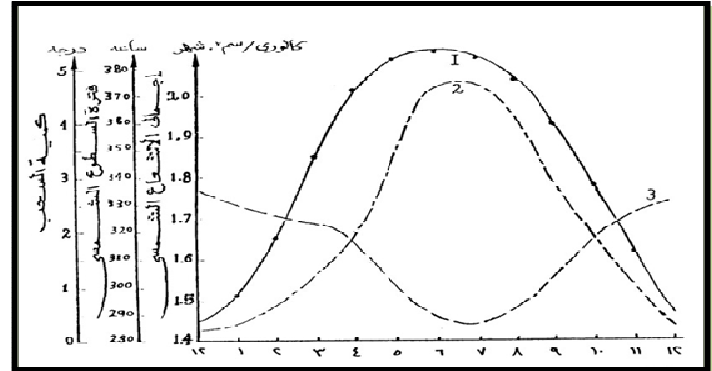

$$
\text { شكل (1) التغير السنوي لإجمالي الإشعاع الشمسي }
$$

(1) الداخل إلى الأرض (r) أثناء فترات السطوع الشهرية (r) المتوسط الشهري لتكوين السحب

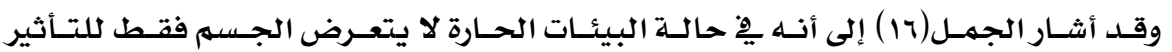

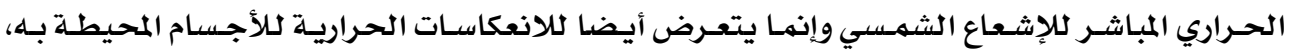
ذلك مها يجعل درجـة حرارة الجو ليست مـترتبـة على حدة الإشعاع الشمسي، وإنهـا هـي نتيجـة مباشـرة

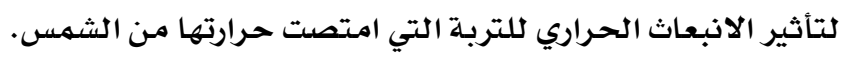

بـ الإجهاد الحراري والإجهاد الفسيولوجي: Thermal \& Physiological stress

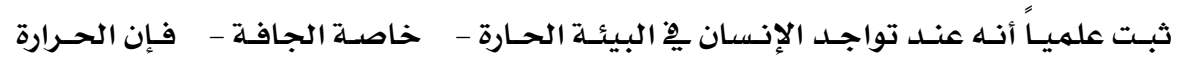
المتولدة داخل جسهـه لا تعتبر المصلدر الرئيسي لشعوره بعـدم الراحسة وإنها تظل الحـرارة المكتسبـة مـن الخارج هي مصدر إجهاده الحراري(10) . وقد ثبت أنه بينهـا تصل كهية الحـرارة الداخلـة للجسسم إلى ( . .ع ) كيلـو سعر حـراري عندـ

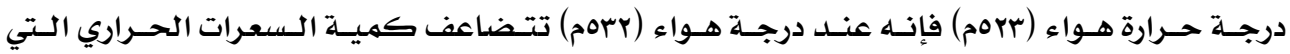

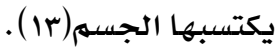

كما ثبـ أنه عند تعرض الإنسـان لجرعة كافيلة مـن التأثير الحراري للشمس يرتفـع معـدل تبادل الغازات داخل الجسهم ويزيـد معـدل أداء الكلى ويـغير الدور الوظيفي للنظـام العصبي المركزي

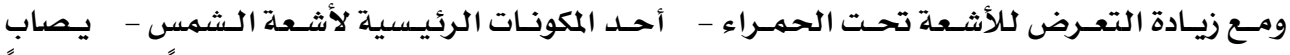

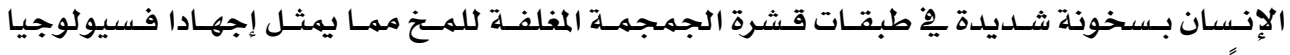

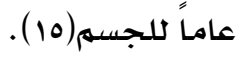

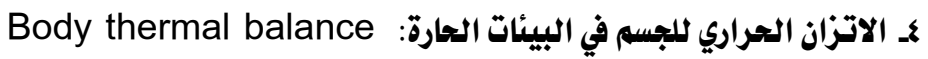
يتحقق الإحسـاس بادراحة الفسيولوجية العـامـة للجسسم إذ حسدث اتزاناً حرارياً بـين الحـرارة

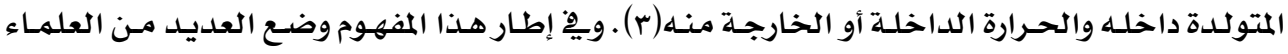

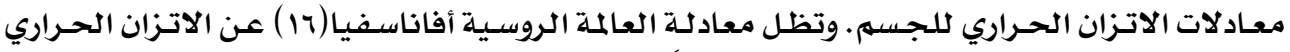

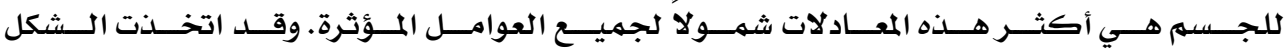
الرياضي الآتي(17): 
$\mathrm{T}_{\mathrm{m}}+\mathrm{T}_{\mathrm{c}}=\mathrm{T}_{\text {rad }}+\mathrm{T}_{\text {conv }}+\mathrm{T}_{\text {cond }}+\mathrm{T}_{\text {evap.gs }}+\mathrm{T}_{\text {evap.ls }}+\mathrm{E}_{\text {vap.b }}+\mathrm{T}_{\text {h.e }}=\mathrm{D}$

حيث أن:

الطاقة الحراريـة المتولدة داخل الجسهم، بالفولت.

$T_{\mathrm{m}}$

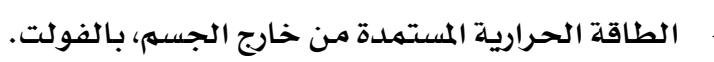

$\mathrm{T}_{\mathrm{C}}$

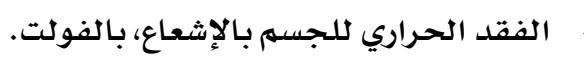

$\mathrm{T}_{\text {rad }}$

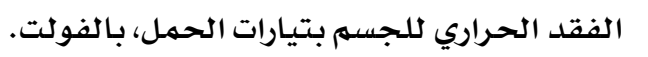

$T_{\text {conv }}$

- مالفقد الحراري للجسمى بالتوصيل للجسهم، بالفولت.

$\mathrm{T}_{\text {cond }}$

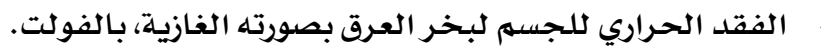

Tevap.gs

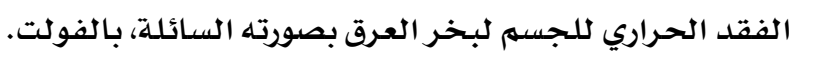

Tevap.ls

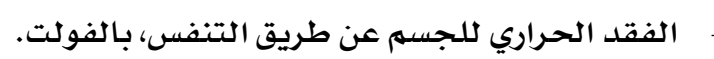

Tevap.b

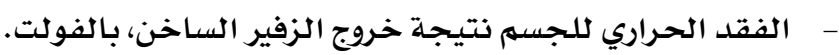

$T_{\text {h.e }}$

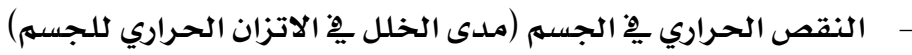

D

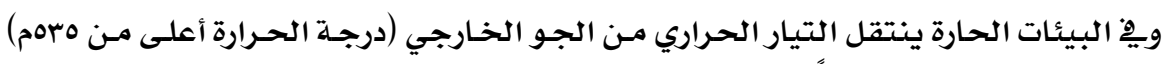

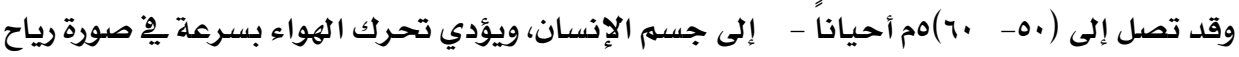

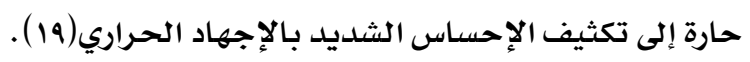

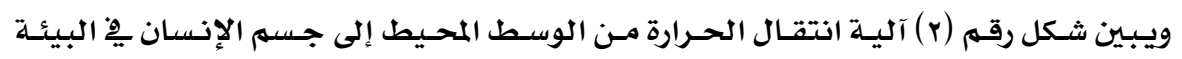

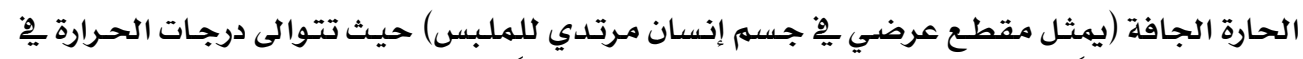

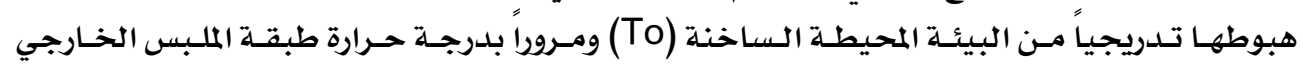

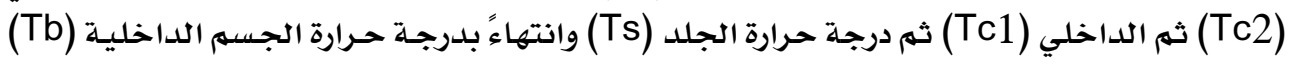

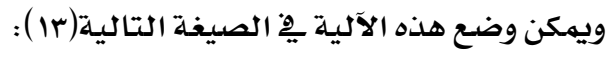

$$
\mathrm{T}_{\mathrm{o}}>\mathrm{T}_{\mathrm{c} 2}>\mathrm{T}_{\mathrm{c} 1}>\mathrm{T}_{\mathrm{s}}>\mathrm{T}_{\mathrm{b}}
$$

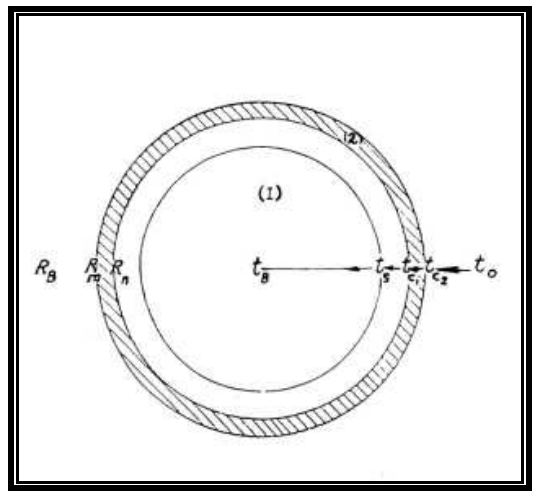

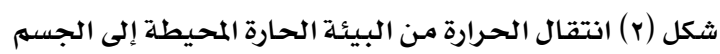

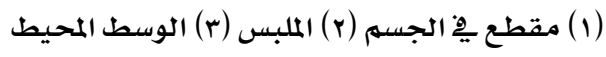


هـ المقاومة الحرارية للملبس Clothing thermal resistance

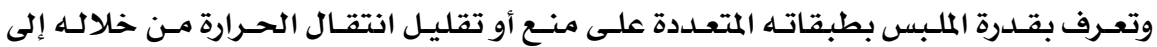

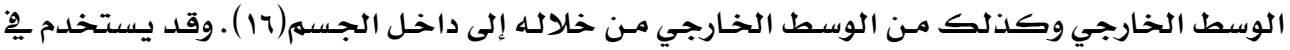

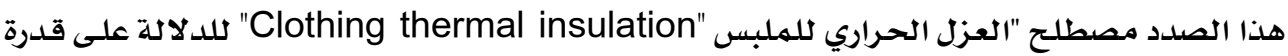

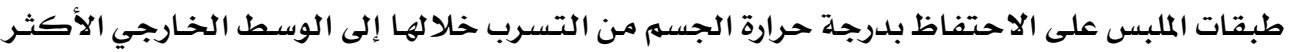

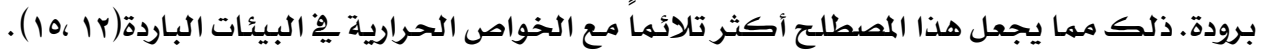

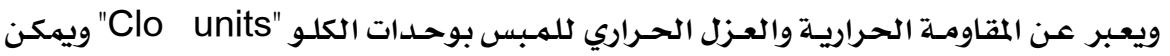

$$
1 \mathrm{clo}=0.155 \mathrm{~km}^{2} / \mathrm{w}
$$

حساب قيمة الكلو من المعادلة الآتية:

وبذلك فإن "الكلو" الواحد يمثل كمية العزل الحـراري الدي يتيح لشخص يِّح حالـة ثبـات

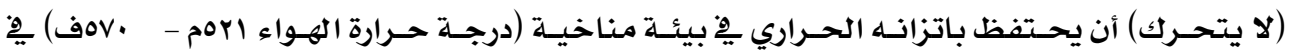

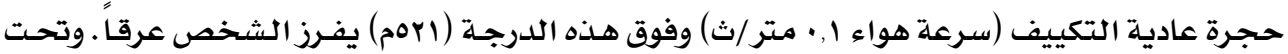

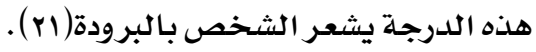

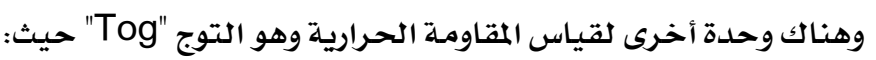
1 tog $=0.1 \mathrm{~m}^{2} \mathrm{k} / \mathrm{w}=0.645 \mathrm{clo}$

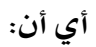

$$
1 \text { clo }=1.55 \text { togs }
$$

\section{الخطة الملهية للبحث اختيار عينات البحث}

تتميز العينات النسجية المختارة من السوق المحلي (عددv) سبعة عينات بالمواصفات الآتية: ا- تركيبات شعرية صناعية أو تركيبية (بولي استر خالص، بولي استر نايلون).

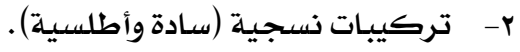

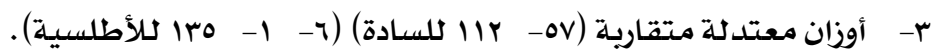
التحليل النسجي للعينات:

تم إجراء الاختبارات الآتية لتحليل المواصفات النسجية الدقيقة لعينات البحث:

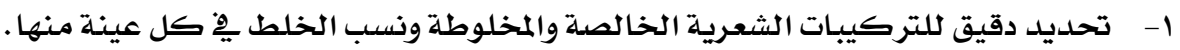

$$
\text { r - r - r التركيب النسجي. }
$$

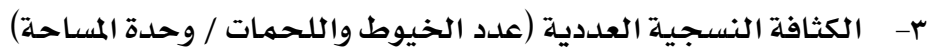

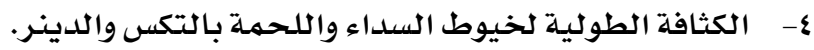

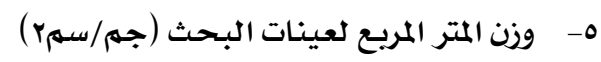




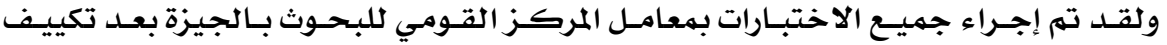

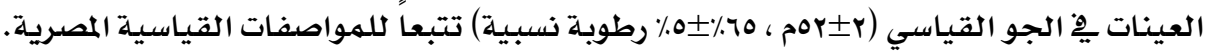

القياسات المتعلقة بجودة الخواص الحرارية:

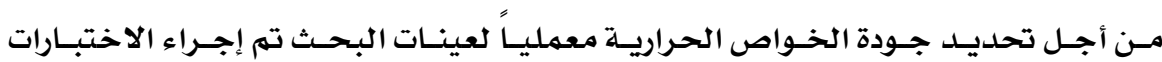

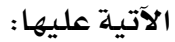

1- إس قياس سمك بالمليمتر لكل عينة.

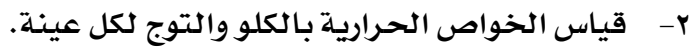

r- تقدير المسامية باستخدام معاملات التغطية لكل عينة.

وسائل الاختبار والأجهزة المستخدمة:

1- تقديروزن المتر المريع لأقمشة الملابس تحت البحث.

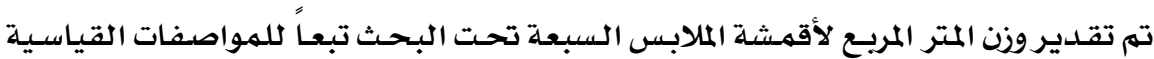

الأمريكية (10).

r- تقدير الكثافة الطولية للسداء واللحمة يِّ عينات البحث:

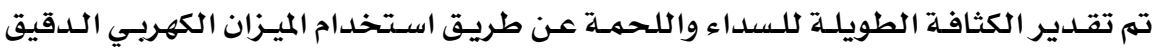

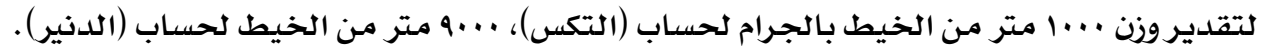

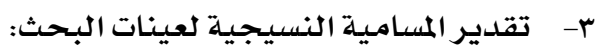

تم تقـدير المسامية النسـية لعينـات البحـث عن طريـق حسـاب معـاملات التغطيـة للسـداء

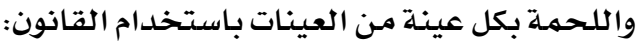

$$
K_{1}=\frac{n_{1}}{\sqrt{N_{1}}} \quad K_{2}=\frac{n_{2}}{\sqrt{N_{2}}}
$$

n - n1, n2

N1, N2

ثم بعد ذلك حساب معامل التغطية للقماث (Kc) لكل عينة باستخدام القانون:

$$
\text { Kc }=\mathrm{k} 1+\mathrm{k} 2
$$

ونظراً لأن معامل تغطية القماش يعتبر دالة عكسية لمسامية القماش حيث إن معامل تغطية

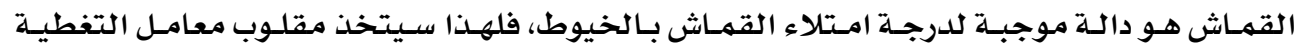

(1/kc) 


$$
\text { ؟- تقدير سمك الأقمشة تحت البحث: }
$$

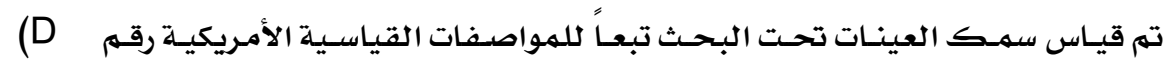

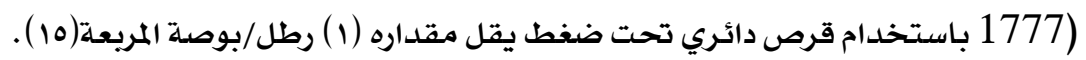

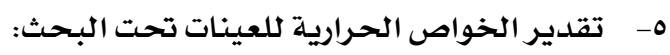

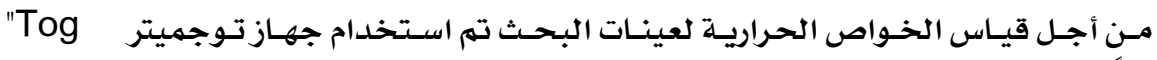

meter"

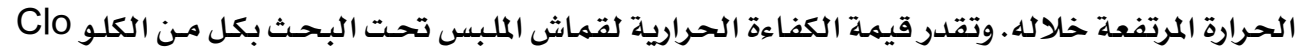

$$
\begin{aligned}
& \text { أو التوج Tog حيث: (1 clo = 1.55tog). } \\
& \text { أ- وسيلة ونظريـة الاختبار: }
\end{aligned}
$$

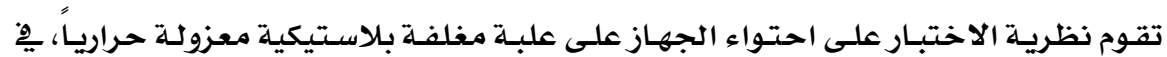

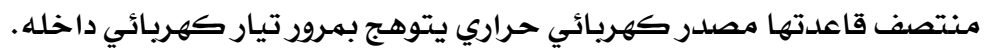

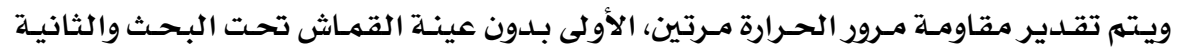

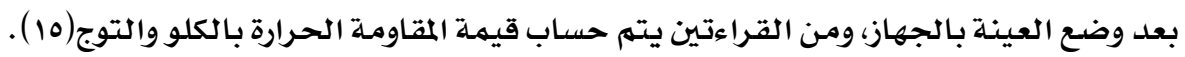

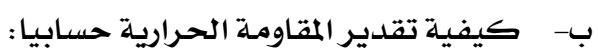

لحساب الفقد يِّ الطاقة (نتيجة وضع العينـة وتختلف قيمتهه مـن عينـة لأخرىى) تلدون كل

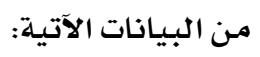

ا- فرق التشغيل: زمن مـرور التيار الكهربي من القراءة الأولى إلى آخر قراءة.

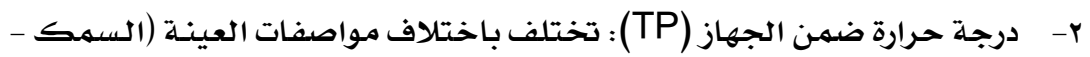

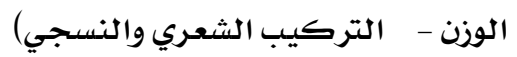

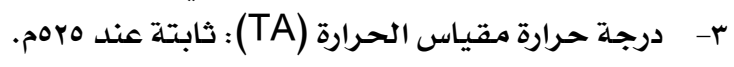

ع- مساحة صحن الجهاز: ثابتة وتساوي (ع -..) ).

يجب أولا حساب الفقد ِِِ طاقة الجهاز باستخدام المعادلة الآتية:

$$
P_{\mathrm{ul}}=\frac{18 x(ف ر ق)}{3600}
$$

$$
\begin{aligned}
& \text { حيث: } \\
& \text { - تدل على قيمة التيار المار بِّه السلك الحراري بالجهاز. }
\end{aligned}
$$

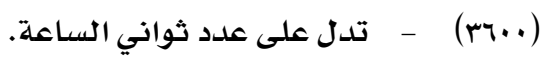

$$
\begin{aligned}
& \text { تحسب قيمة الانتقال الحراري (U1) بعد رفع العينة مـن القانون: } \\
& U_{1}=P_{U 1} \div A\left(T_{P}-T_{A}\right) \\
& \text { تحسب قيمة الانتقال الحراري (U2) باستخدام العينة من القانون: }
\end{aligned}
$$




$$
\mathrm{U}_{2}=\frac{\mathrm{U}_{\mathrm{TP}} \times \mathrm{U}_{1}}{\mathrm{U}_{\mathrm{TP}}-\mathrm{U}_{1}}
$$

$$
\begin{aligned}
& \text { حيث: } \\
& \text { UTP } \\
& \text { تحسب المقاومة الحرارية (R) كقلوب للانتقال الحراري (U2) بالقانون: } \\
& R=\frac{1}{U_{2}} \\
& \text { تحسب قيمة المقاومـة الحرارية (R) بوحدات التوج (Togs) والكلو (Clo). }
\end{aligned}
$$

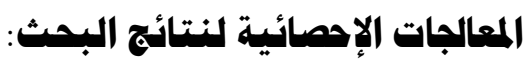

للكـشف عـن طبيعـة وقـوة العلاقـات بـين نتـائج البـحـث اسـتخدام أفضـل وأقـوى الوســائل

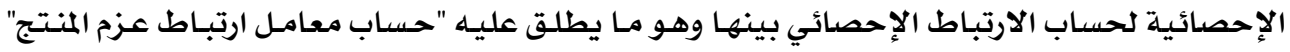

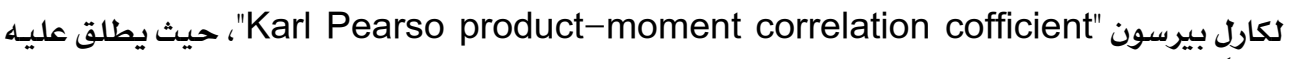
أيضاً (The PPMCC) أو (The PCC) وذلك باستخدام الصيغة الرياضية الآتية(10):

$$
\begin{aligned}
& r=\frac{\sum_{i=1}^{n}\left(X_{i}-\bar{X}\right)\left(Y_{i}-\bar{Y}\right)}{\sqrt{\sum_{i=1}^{n}\left(X_{i}-\bar{X}\right)^{2}} \sqrt{\sum_{i=1}^{n}\left(Y_{i}-\bar{Y}\right)^{2}}} \\
& \text { حيث: } \quad \text { - X, } \\
& \text { - } \bar{X}, \bar{Y}
\end{aligned}
$$

\section{النتائج والمناقشة \\ أولا: عرض لنتائج البحث}

1- عرض لنتائج قياسات المواصفات البنائية لأقمشة الملابس الخارجية موضوع البحث:

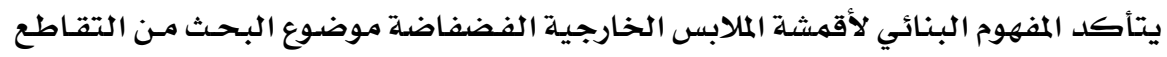

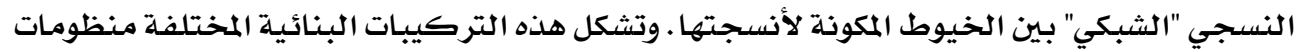

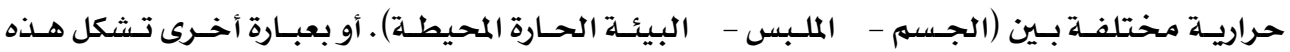

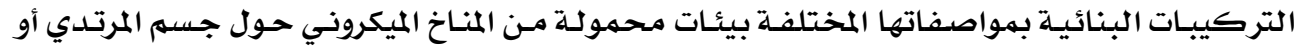

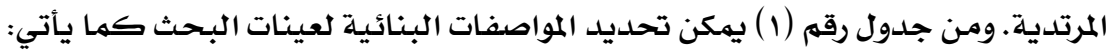

$$
\text { أ- التركيب الشعري: }
$$

العينات رقم (1) ، (ع) ، (v) منسوجة من خيوط من البولي استر الخالص سداء ولحمـات. 


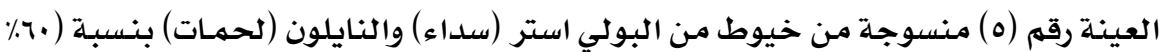

بولي استر + •ع٪ نايلون)

العينـات أرقام (r) ، (r) ، (ج) منسـوجـة مـن خيوط النـايلون (سـاء) والبـولي استر (لحمـات)

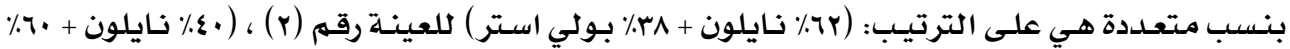

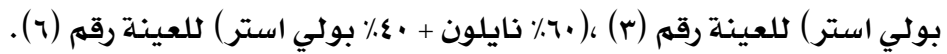
ب- التركيبات النسجية:

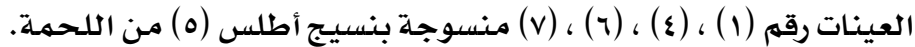

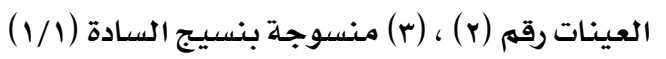

العينة رقم (ه) منسوجة بنسيج السـادة الممتد غير المنتظم من السداء (r/r) ويوضح الشكل رقم (r) صور لأشكال التركيبات النسجية الثلاثة.

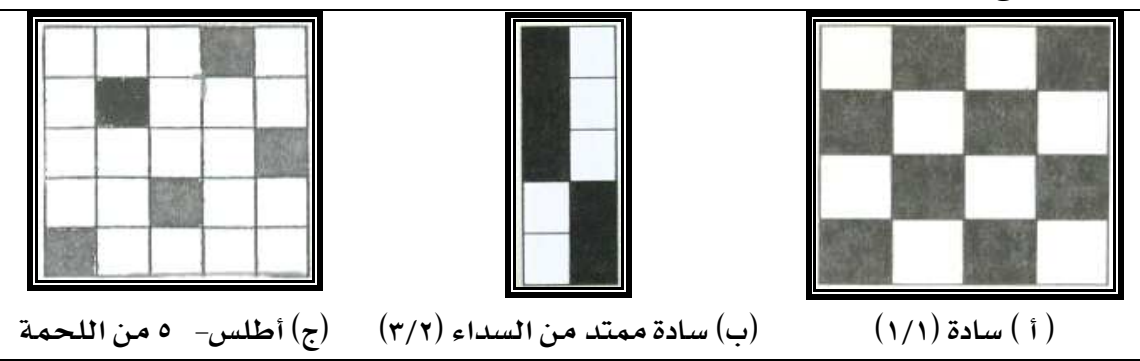

شكل رقم (r) التركيبات النسجية المستخدمة ِِّ نسج عينات البحث

ت- الكثافات النسجية (عدد خيوط السداء واللحمات يِّوحدة القياس - السنتيمتر)

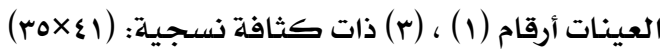

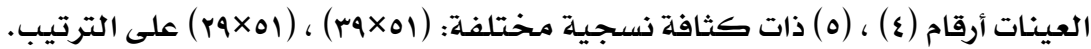

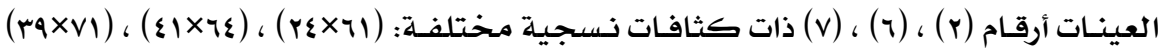

على الترتيب.

ث- الكثافات الطولية بالتكس والنمر بالدنير لخيوط السداء واللحمة يِّ العينات:

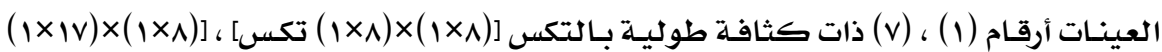

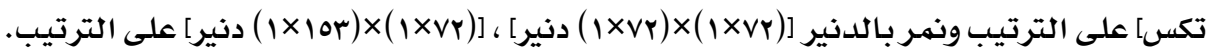

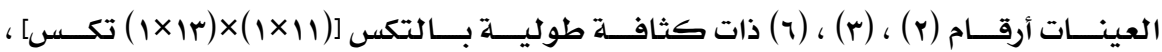

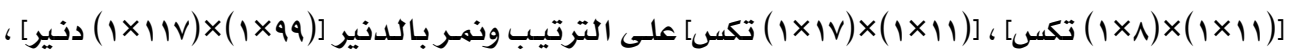

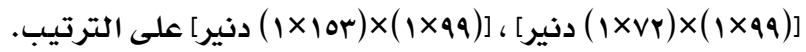

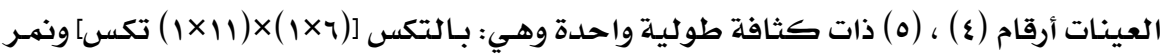

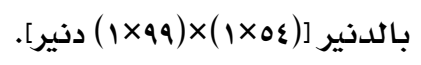




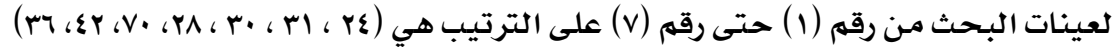
جدول رقم (1) المواصفات البنائية لعينات البحث

\begin{tabular}{|c|c|c|c|c|c|c|c|c|c|}
\hline \multirow{3}{*}{ لمالأقمشة } & \multicolumn{4}{|c|}{ الكثافة الطولية بالتكس والنمر بالدنير } & \multicolumn{2}{|c|}{ الكثافة النسجية/ سم } & \multirow{3}{*}{ التركيب النسجي } & \multirow{3}{*}{ التركيب الشعري ونسب الخلط } & \multirow{3}{*}{ رقينة } \\
\hline & \multicolumn{2}{|c|}{ دنير } & \multicolumn{2}{|c|}{ تكس } & \multirow{2}{*}{ ل لحمات } & \multirow{2}{*}{ 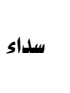 } & & & \\
\hline & | لحمات & 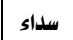 & 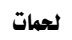 & 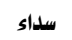 & & & & & \\
\hline rr & $(I \times r r)$ & $(1 \times r r)$ & $(1 \times \wedge)$ & $(1 \times \wedge)$ & ro & $\S$ & أطلسه من اللحمة & بولي استر للسداء واللحمة (•l/) & 1 \\
\hline ri & $(I \times I V)$ & $(1 \times 99)$ & $(1 \times 14)$ & $(1 \times 11)$ & $r \xi$ & 71 & السادة (1/1) & 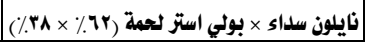 & r \\
\hline r. & $(1 \times r r)$ & $(1 \times 99)$ & $(1 \times \wedge)$ & $(1 \times 11)$ & ro & $\S$ & السادة (1/1) & نايلوز سلداء × بولي استر لحمة (•٪/ × •7٪) & $r$ \\
\hline ra & $(1 \times 99)$ & $(1 \times 0 \xi)$ & $(1 \times 11)$ & $(1 \times 7)$ & ra & 01 & أطلسه من اللحمة & بولي استر للسداء واللحمة (•l/\%) & $\varepsilon$ \\
\hline ve & $(1 \times 99)$ & $(1 \times \Delta \xi)$ & $(1 \times 11)$ & $(1 \times 7)$ & rq & 01 & سادة متتد من السداك(r/ & 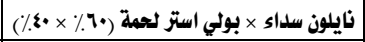 & 0 \\
\hline sr & $(1 \times 10 r)$ & $(1 \times 99)$ & $(1 \times 1 v)$ & $(1 \times 11)$ & rq & $n$ & أطلسه من اللحمة & 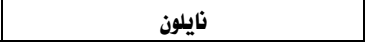 & 7 \\
\hline ma & $(1 \times 10 r)$ & $(1 \times r r)$ & $(1 \times 1 y)$ & $(1 \times \wedge)$ & $\$$ & $7 \xi$ & أطلسه من اللحمة & بولي استر للسداء واللحمة (••اء) & $\checkmark$ \\
\hline
\end{tabular}

r - نتائج قياس المقاومـة الحرارية لعينات البحث:

يتبـين من جدول رقم (r) القيهم المتعلقة بتقدير المقاومـة الحراريـة لعينـات البحـث باستخدام

جهاز توجميتر Togmeter تبعاً للمواصفات القياسية البريطانيـة (10 ). جدول رقم (r) القيه المتعلقة بتقدير المقاومة الحرارية لعينات البحث

\begin{tabular}{|c|c|c|c|c|c|c|}
\hline $\begin{array}{c}\text { المقاومة العرارية بالتوج } \\
\text { (TOGS) }\end{array}$ & المقاومة العرارية & $\begin{array}{c}\text { المقاومة العرارية } \\
\text { (R) }\end{array}$ & | باستخدام العينة(u1) العتال العراري & \begin{tabular}{|c|} 
الاتتقال الحراري بدونة العينة \\
(u1
\end{tabular} & | الفقد في طاقة الجهاز & |رقم العينة \\
\hline $1, r r$ & $r, \bullet$ & •, & $r, r \cdot$ & r, Yo & 1, ro & 1 \\
\hline 1,17 & $1, \wedge$. & •, rr & ץ, . . & $r, \cdot \cdot$ & $1, r \cdot$ & $r$ \\
\hline $1,1$. & I,ve. & • rq & $r, \Lambda$. & $r, 17$ & 1, ro & $r$ \\
\hline I,rr & $r, \cdot r$ & • & $r, 10$ & $r, r$. & 1,10 & $\xi$ \\
\hline 1,11 & $1, \wedge \xi$ & •, rV & r.,. & $r, 90$ & 1,ro & 0 \\
\hline I, rY & 1,91 & $\cdot, r \cdot$ & r, ro & $r, \wedge \cdot$ & $1, r \cdot$ & 1 \\
\hline I,rr & $r, \bullet A$ & •, rr & ri, & $r, r$. & 1,10 & $r$ \\
\hline
\end{tabular}

r- نتائج قياس سمك عينات البحث:

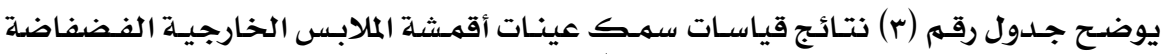

موضوع البـحث بـامليهتر على جهاز قياس السمك تبعاً للمواصفات القياسية المصرية(م). 
جدول رقم (r) نتائج قياسات سمك العينات تحت البحث

\begin{tabular}{|c|c|c|c|c|c|c|c|}
\hline$\checkmark$ & 9 & 0 & $\varepsilon$ & $r$ & r & 1 & رقم العينة \\
\hline$\cdot, 07$ & $\cdot, \$ 1$ & $\cdot, \mathrm{r} \Lambda$ & $\cdot, r v$ & $\cdot, 19$ & $\cdot$, Ir & $\cdot, r q$ & سمك العينة بالمليمتر \\
\hline
\end{tabular}

ع- نتائج قياس أوزان المتر المريع بالجرام لعينات البحث:

يوضح جدول رقم (r) نتائج قياس أوزان المتر المربع لعينات البحث بالجرام (جم/مr ) جدول رقم (ع ) نتائج قياسات أوزان المتر المربع لعينات البحث المثر

\begin{tabular}{|c|c|c|c|c|c|c|c|}
\hline$\checkmark$ & 7 & 0 & $\varepsilon$ & $r$ & r & 1 & رقم العينة \\
\hline iro & Irs & 111 & 1.7 & $1 . r$ & vi & $1 \cdot v$ & وزن المتر المربع بالجرام (جم/مץ) \\
\hline
\end{tabular}

0- نتائج تقدير درجة المسامية لعينات البحث:

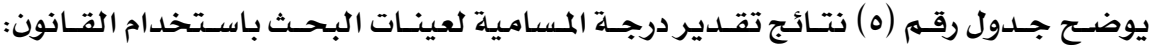

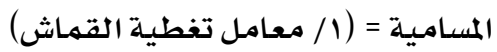
جدول رقم (ه) نتائج تقدير المسامية لعينات البحث

\begin{tabular}{|c|c|c|c|c|c|c|c|}
\hline v & 9 & 0 & $\varepsilon$ & $r$ & r & 1 & رقم العينة \\
\hline$r, \wedge$ & ఛ,々 & 1,8 & $r, 0$ & $r, r$ & $r, r$ & $r, Y$ & مسامية العينة (.) \\
\hline
\end{tabular}

ثانيا: مناقشة وتحليل ثتائج البحث ا. فعالية البناء النسجي والكفاءة الحرارية للملابس الخارجية الفضفاضة:

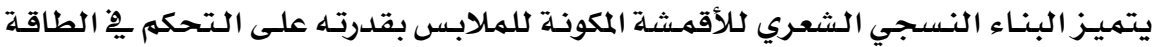

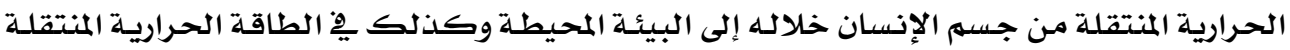

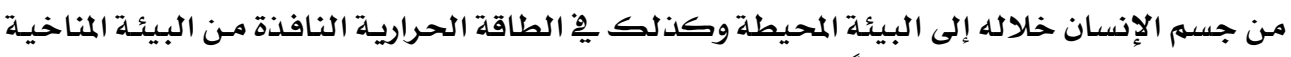

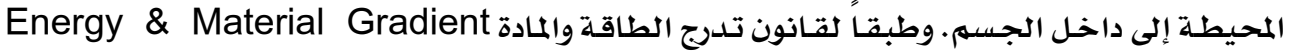

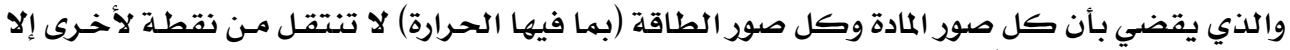

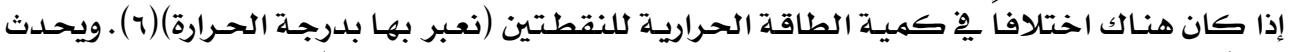

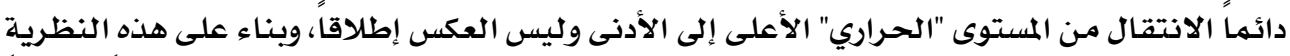

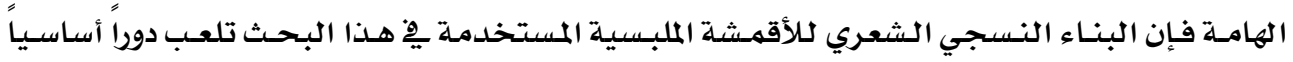

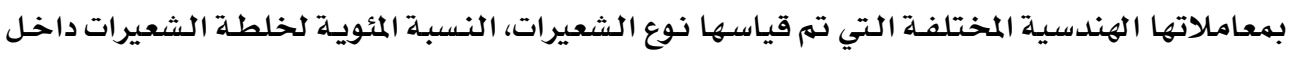

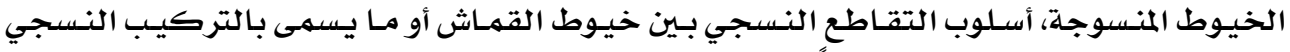

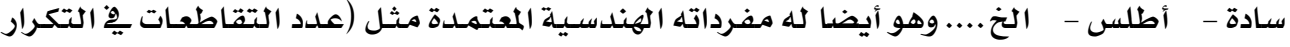

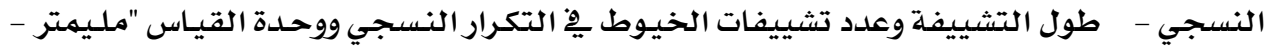

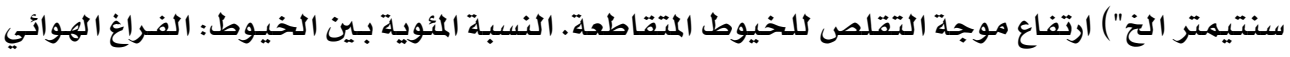




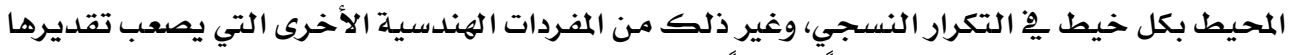

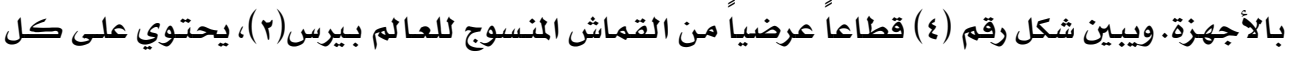

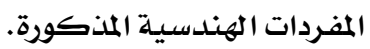

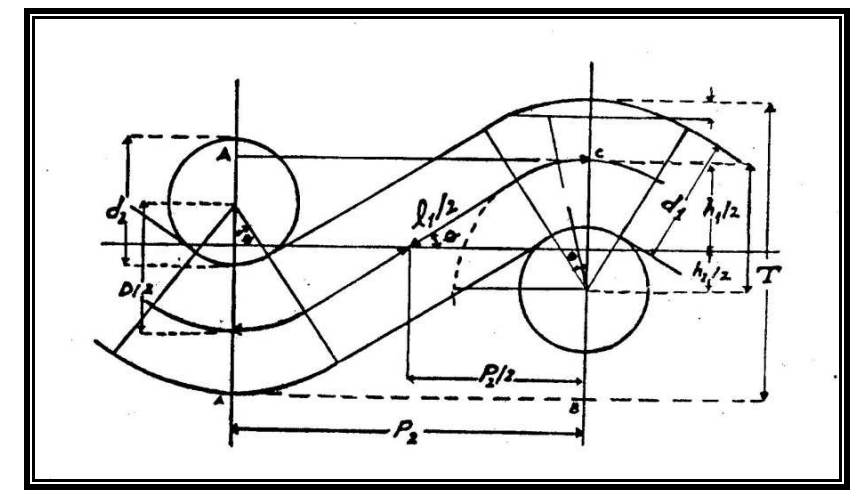

$$
\text { شكل رقم (ع) قطاع عرضي يِّ القماش المنسوج لبيرس }
$$

ولقد أمكن يِّ هذا البحث تقدير مجموعة من المعاملات البنائية الهامـة وهي:

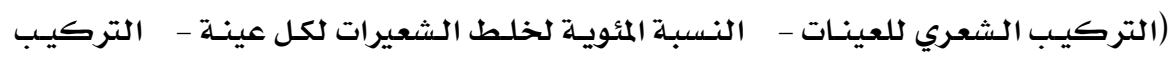

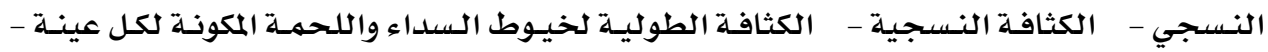

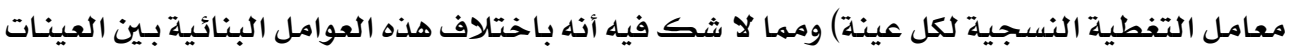

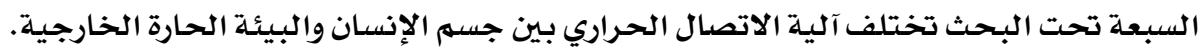

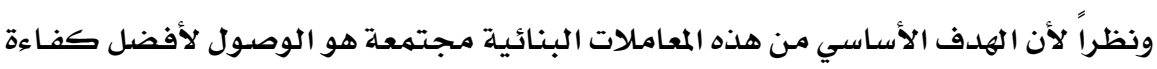

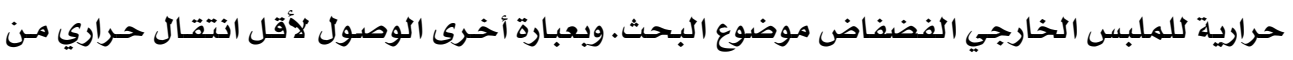

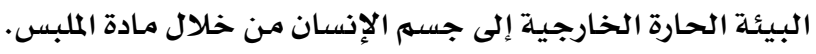

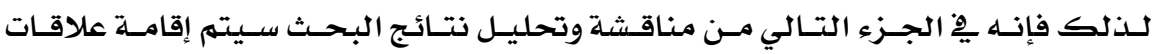

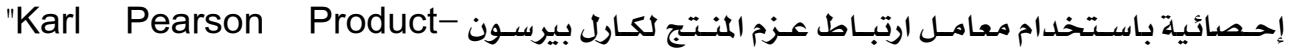
moment Correlation Coefficient" كل من العوامل البنائية المؤثرة وبين المقاومة الحرارية للملابس الخارجية الفضفاضدة المترتبة عليها.

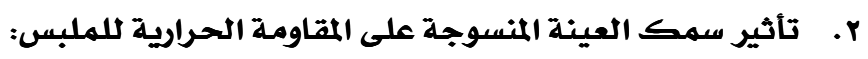
يعتبر السمك من أهم العوامل الأساسية على الخواص الحرارية للهواد .ولا يختلف الأمـر

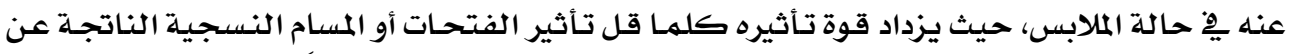

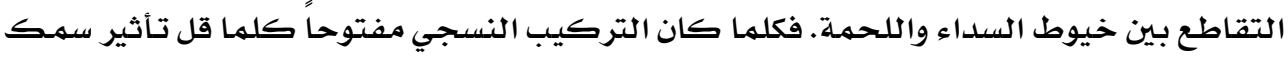

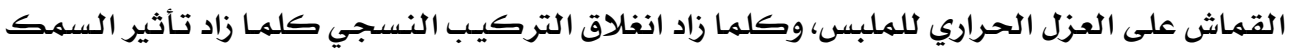




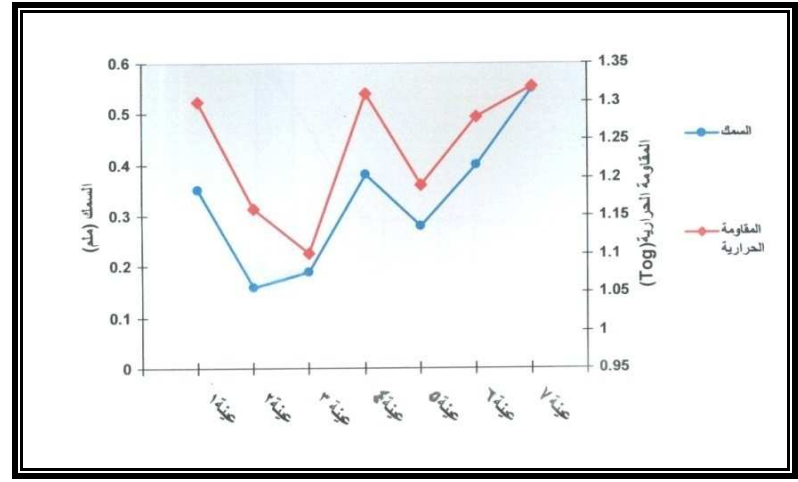

شكل رقم (ه)

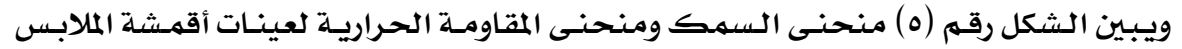

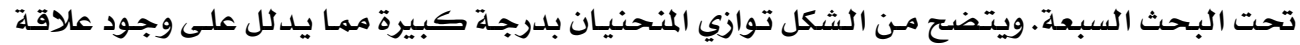

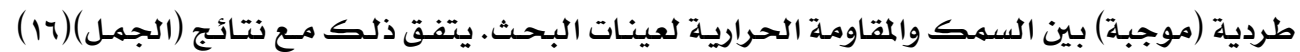

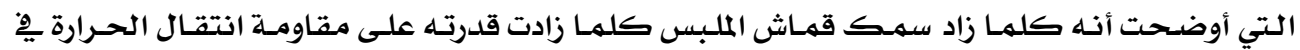

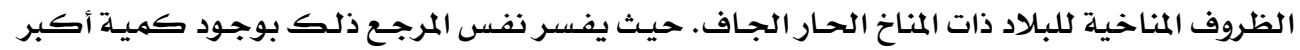

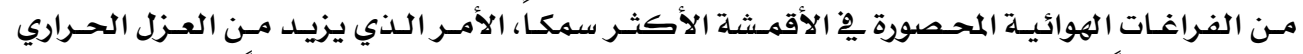

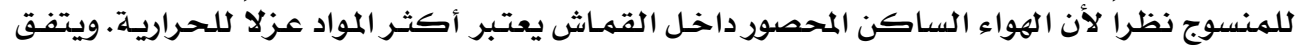

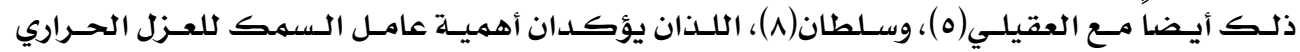
للمهلابس.

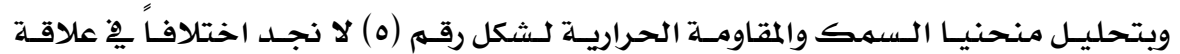

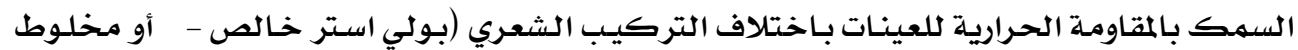
"بولي استر ونايلون) بنسبـه المئويـة المختلفة المبلة.

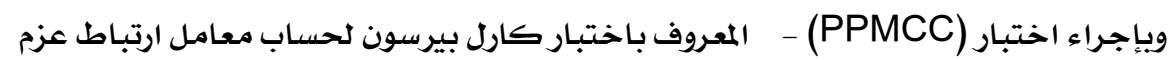

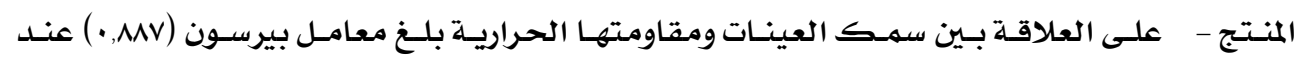

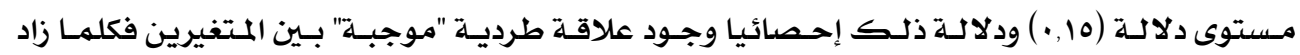

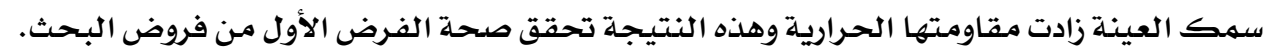
r. تأثير المسامية النسجية على المقاومة الحرارية للمبلس: يتبين من جدول رقم (ه) قيم المسامية النسجية المئويـة للعينـات وعلاقتها بـالعزل الحـراري

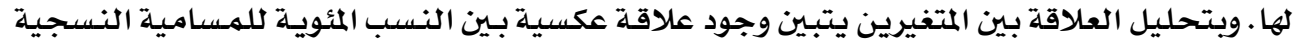

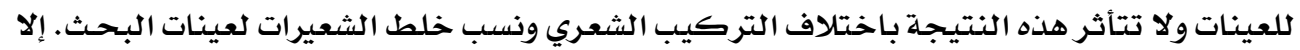

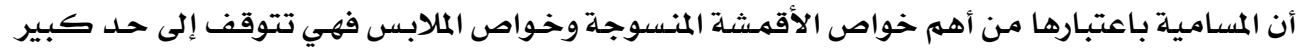

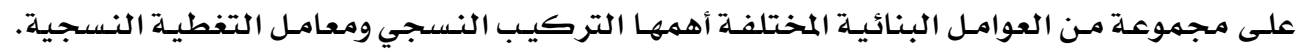




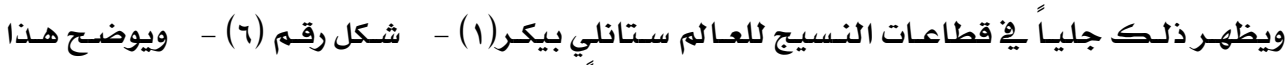

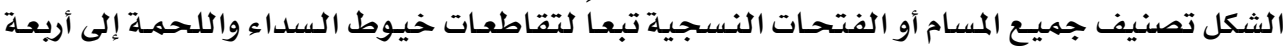

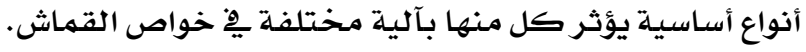

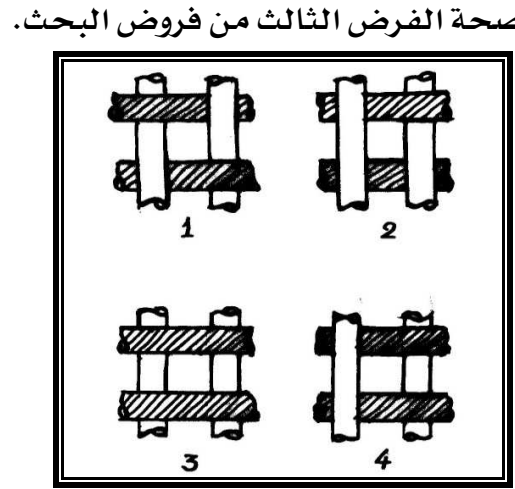

شكل رقم (ج) أنواع المسام أو الفتحات النسجية الرئيسية الهامسة للعالم بيكر

ع.تأثير اختلاف التراكيب النسجية على المقاومة الحرارية لأقمشة الملابس تحت البحث:

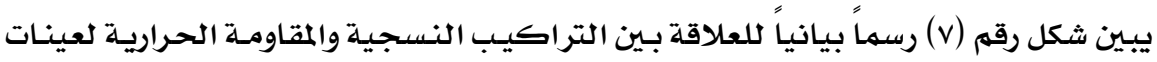

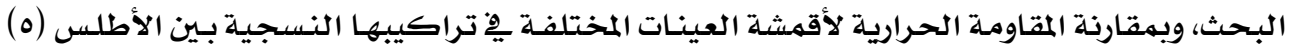

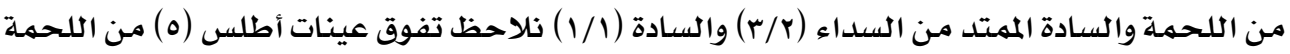

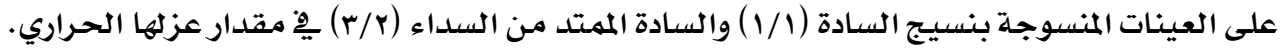

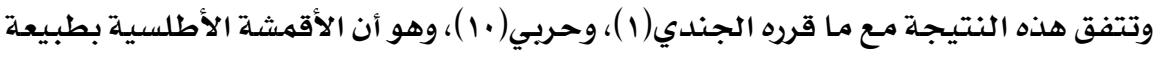

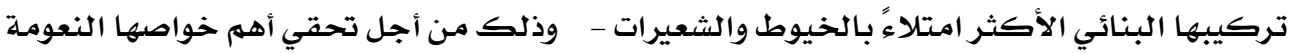

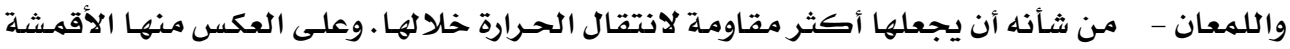

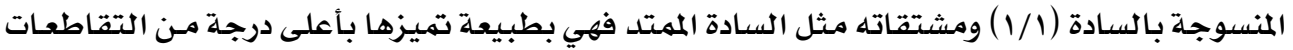

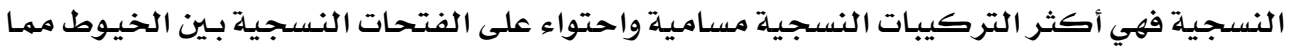

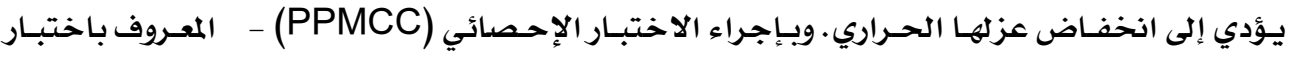

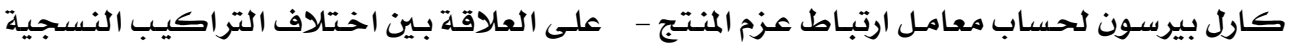

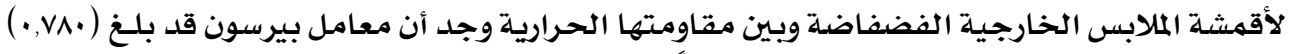

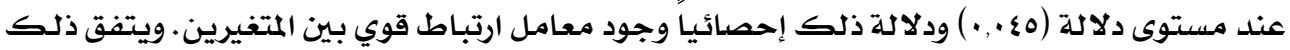

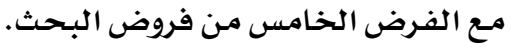




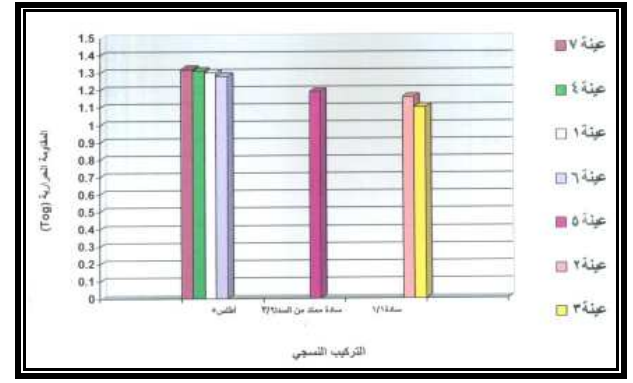

شكل رقم (v)

ه. تأثير اختلاف التركيبات الشعرية للعينات على مقاومتها الحرارية: يبين شكل رقم (^) تأثير اختلاف نوع الشعيرات ونسب الخلط لعينات البحث على مقاومتها

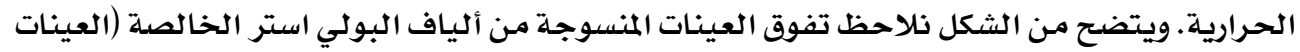

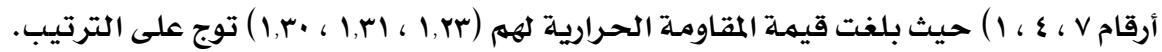
وتلي هذه العينات يِّ قيمة المقاومة الحرارية العينات المنسوجة المخلوطة من شعيرات البولي

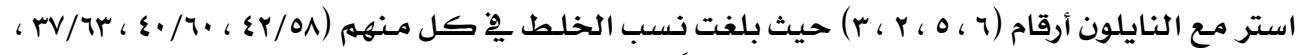

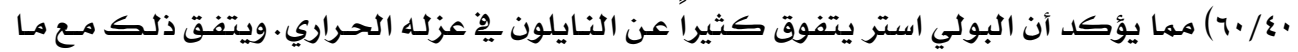

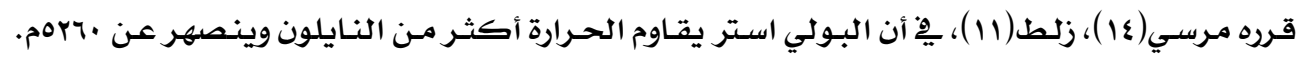

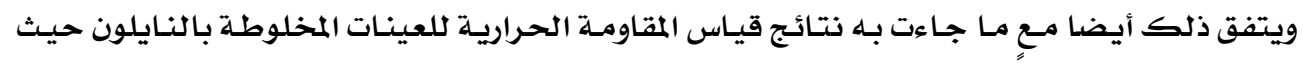

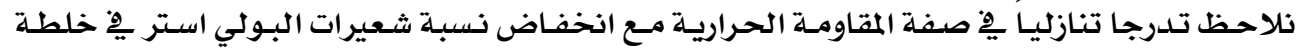

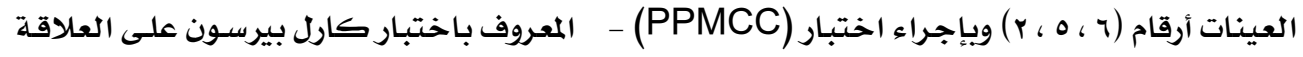

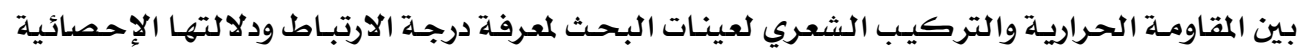

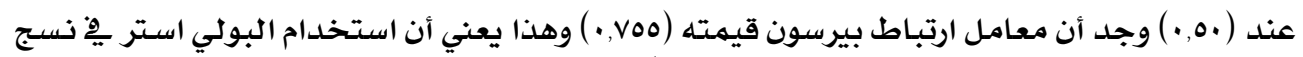

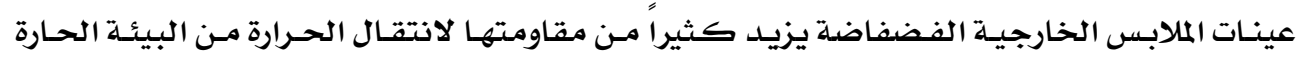

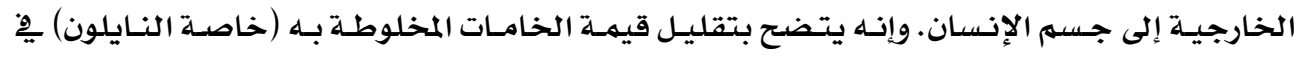

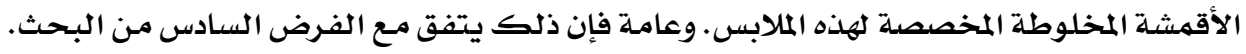

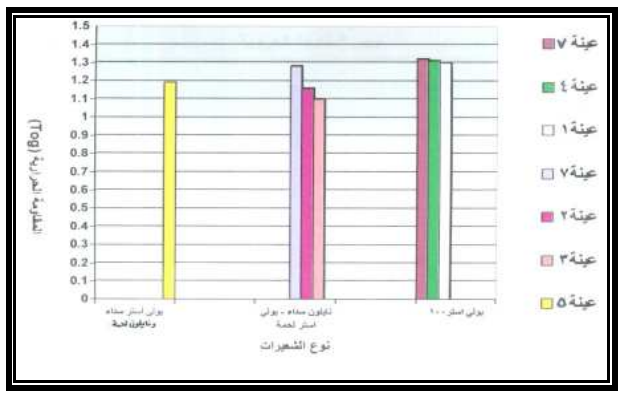

شكل رقم (^) 


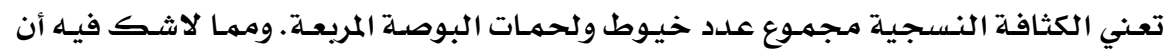

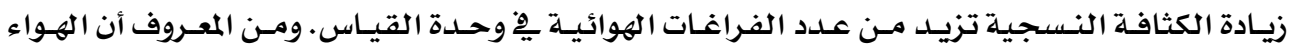

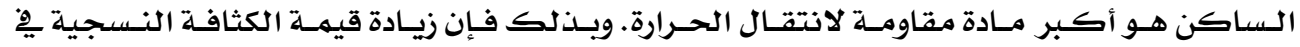

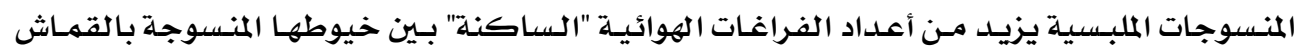

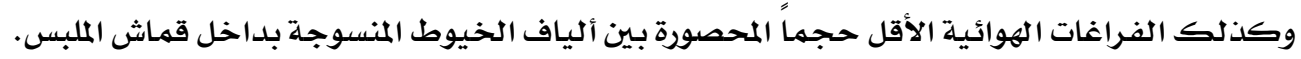

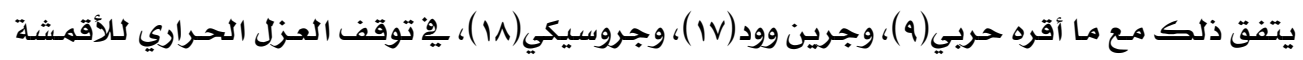

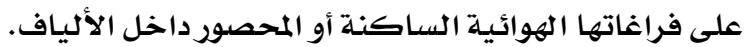

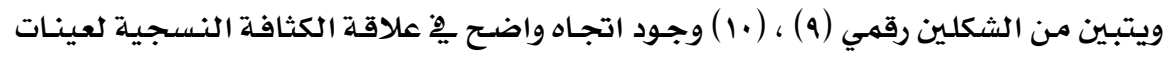

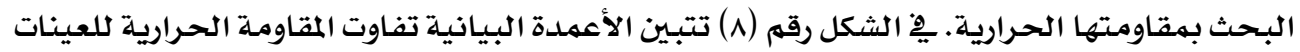

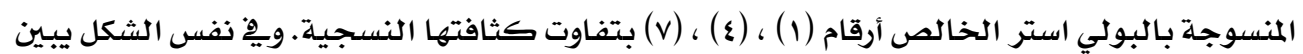

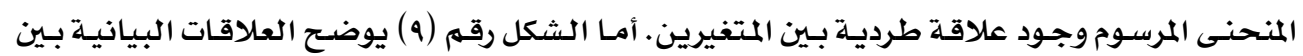

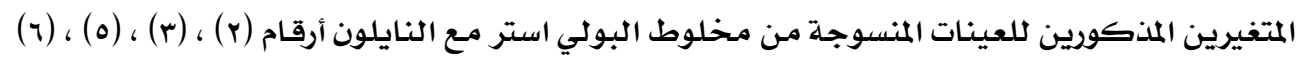

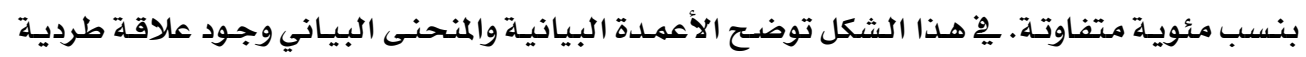
واضحة بين الكثافات النسجية للعينات الأربعة المذذكورة وبين مقاومتها الحئها الحرارية.

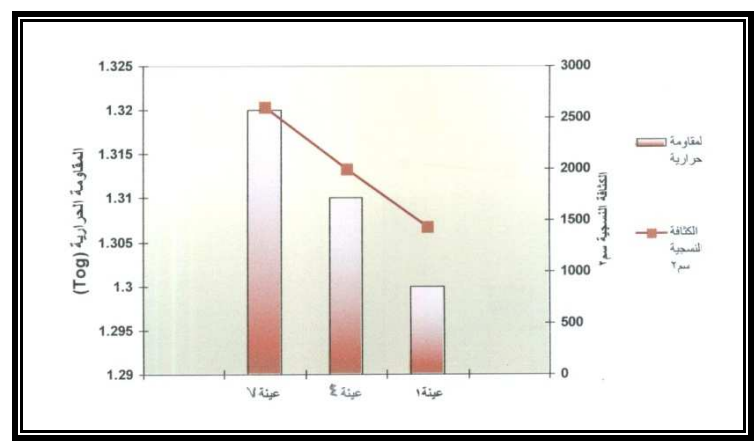

شكل رقم (৭)

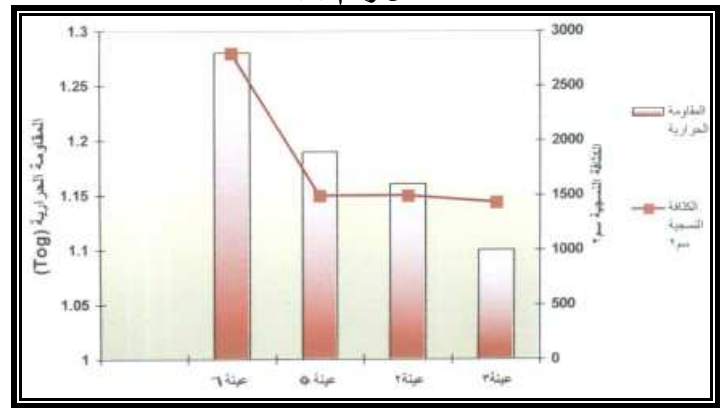

شكل رقم (1.) (1) (1) (1) 
وبإجراء اختبار بيرسون (PPMCC) على العلاقة بين الكثافة النسجية والمقاومسة الحراريـة

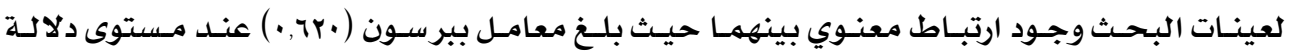

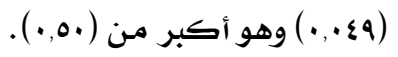

وقد جاءت هذه النتيجة مؤكدة للفرض الثاني من فروض البحث.

V. تأثير معامل تغطية عينات البحث على مقاومتها الحرارية:

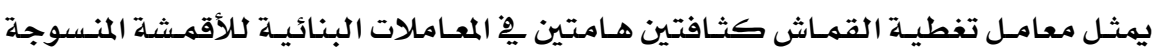

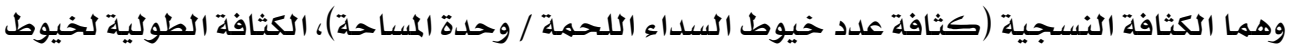

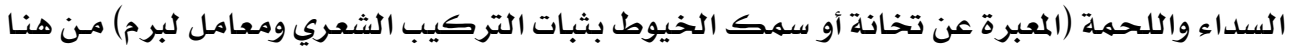

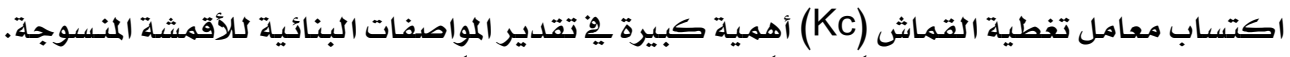

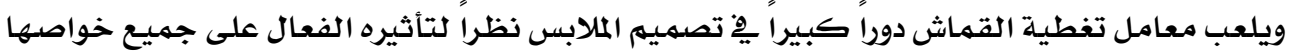
الاستعمالية.

ويرجـع ذلــك أن دالـتي (الكثافـة النسسجية للمنسسوج والكثافـة الطوليسة للخيـوط) اللتـان

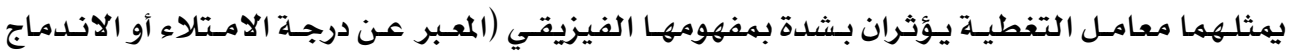

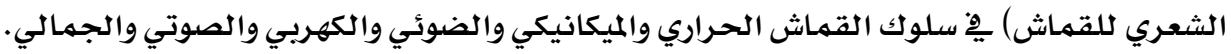

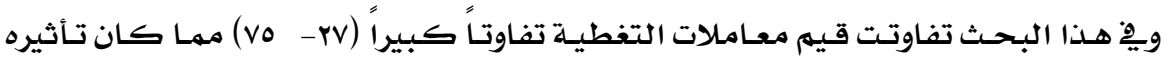

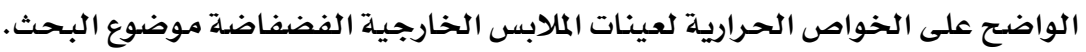

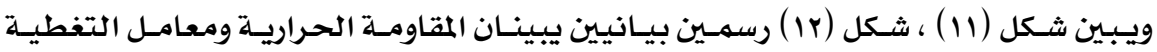

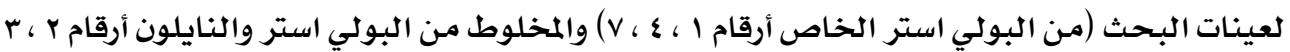

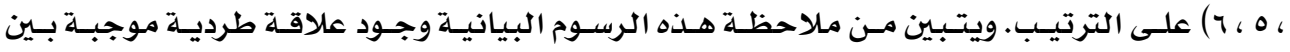

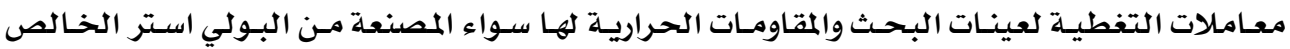

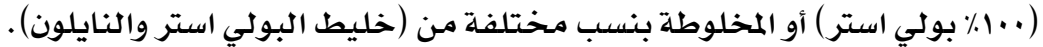

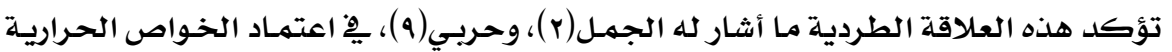

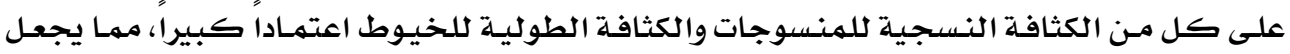

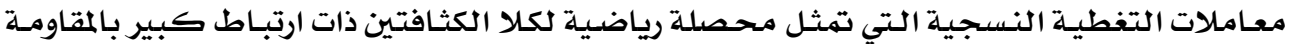
الحرارية للأقمشة.

وبـإجراء اختبـار (PPMCC) المعـروف باختبـار بيرسـون) على العلاقـة بـين هـذين المتغيرين

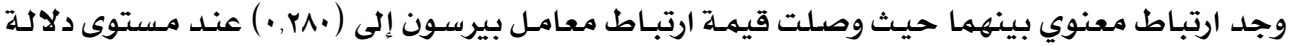

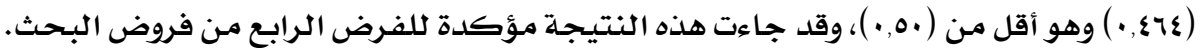




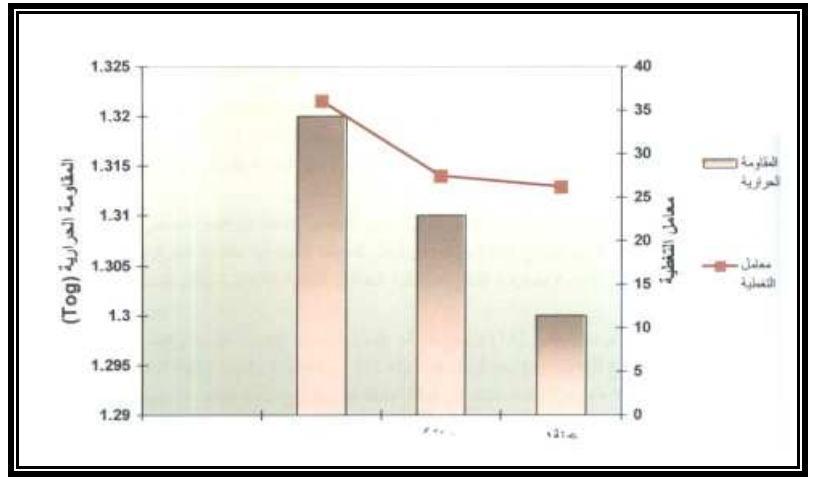

شكل رقم (11) (11)

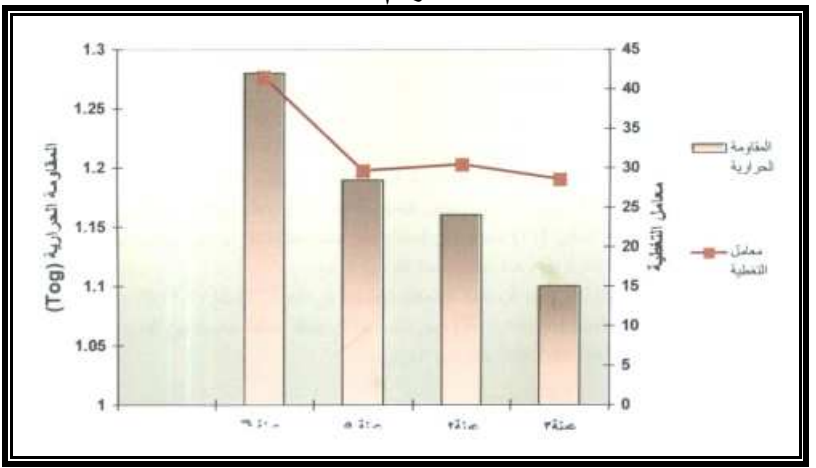

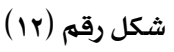

\section{ثالثا: النتائج العامة للبحث}

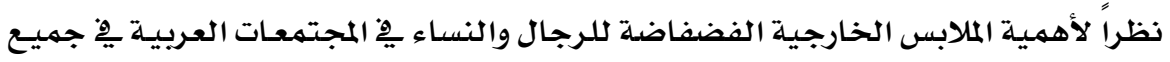

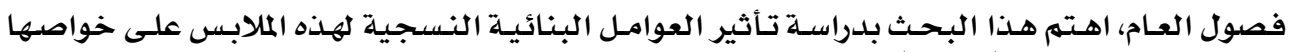

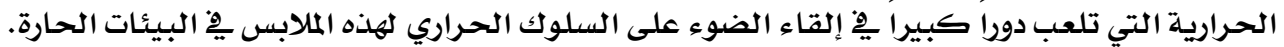
وبعد إجراء القياسـات والتجارب العملية وتحليل ما توصل إليه البحث من نتائج هامـة يمكن

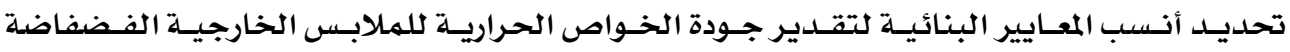

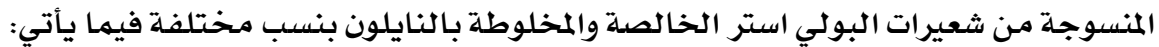

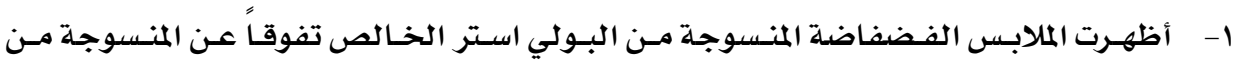

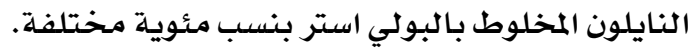

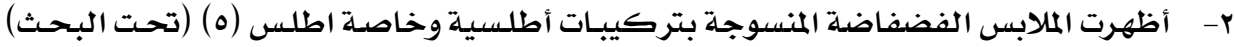

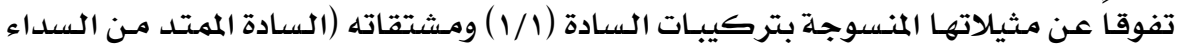

$$
\text { (r/r) موضوع البحث) من مثيالاتها المنسو }
$$




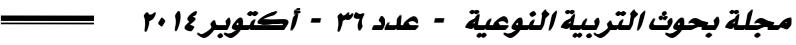

ب- كلما زادت الكثافة النسسجية لأقمشـة الملابس الخارجيـة الفضفاضـة ارتفعت جـودة خواصها

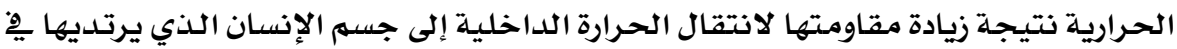

البيئات الحارة.

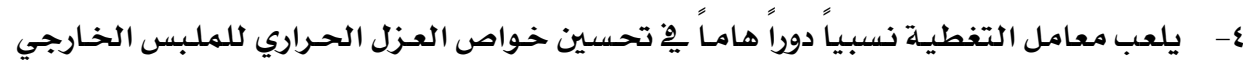
الفضفاض حيث كلما زادت قيمة التغطية النسبيـة زادت مقاومـة الملبس للحرارة الخـارجية.

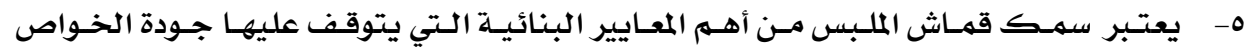

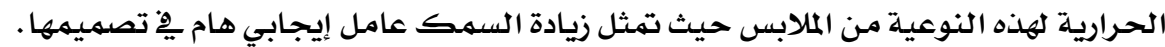

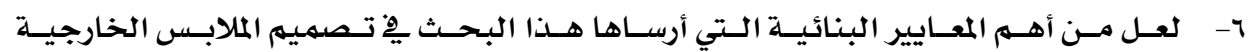
الفضفاضـة هو التأكيد على أهميـة الألياف أو الشعيرات الصنـاعية وعلى رأسها البـولي اسـتر

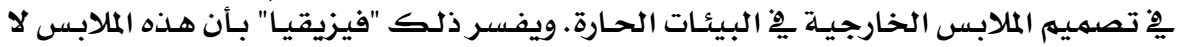

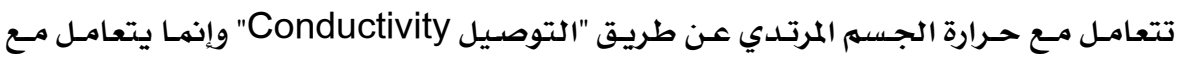
انتقال الحـرارة بتيـارات الحمل والإثعاع لحرارة الشمس والوسط المحيط. مها يحتاج إلى آليـة أخرى تتميز بها أقمشة البولي استر كما أثبت البحرث. يرسي هذا البحث مفـاهيم جديدة يخ فـصميهم الملابس الخارجيـة الفضفاضـة بجميـع أنواعها للرجال والنسـاء والأطفال بهـختلف أعمارهم. ويؤكد على أهميتها الحيويـة لتحقيـق الراحسة

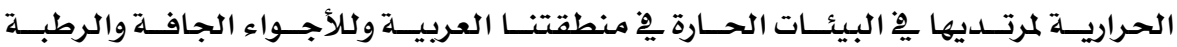
على السواء. ويفسر ذلك بـأن المقاومـة الحـراريـة العاليـة لبعض التركيبـات القهاشـيلة التي توصـل إليها البحثث من شأنها أن توفر على دوام ارتداء الملبس مناخا ميكرونياً يِّا الفراغ الهوائي "المتحركك" المحصور بين الملبس وجسم الإنسسان. ويتميز هذا الفراغ الميكروني "Micro climate" بأنه أقل بكثير يِ درجة حرارة الجو المحيط للبيئة الحارة التي يتواجد فيها المرتدي.

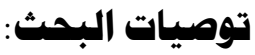

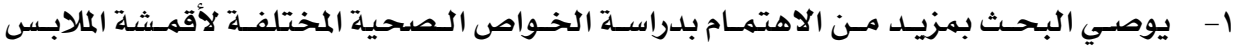

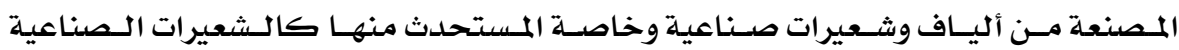
الميكرونية "Micro fibers".

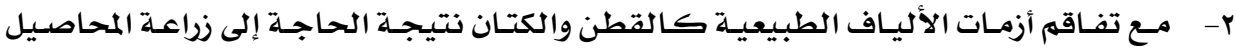

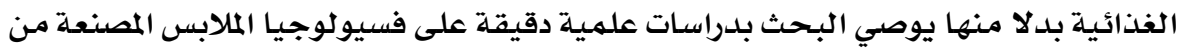
ألياف صناعية ودورها يِّ توفير بـائل للملابس للمناطق الحارة.

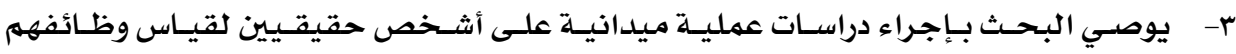

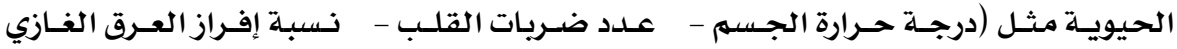
والسـائل) عند ارتداء مثل هذه الملابس فيكون بهثابـة تطبيق فعلي لنتائج هذا البحث. 


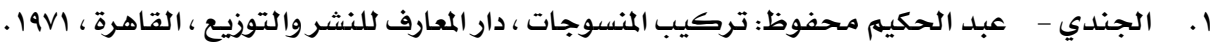

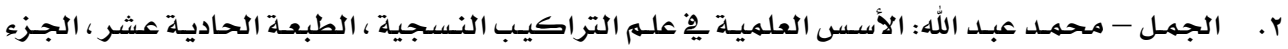

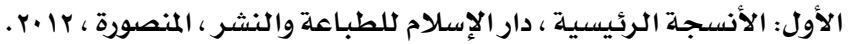

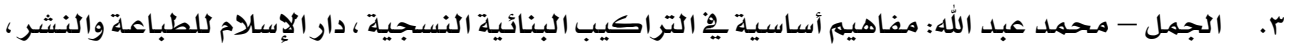

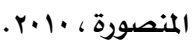

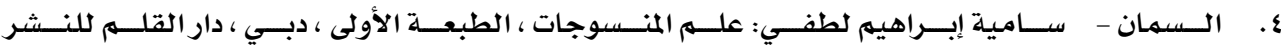

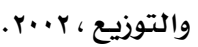
ه. العقيلي - مصطفى: الخـواص الحراريـة للملابس ، رسـالة ماجستير غير منشورة - كليـة الهندسـة ،

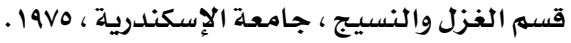

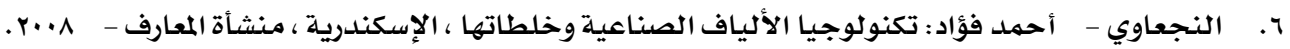

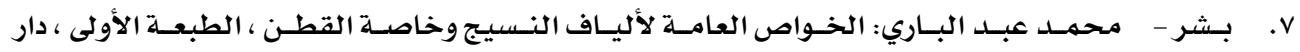

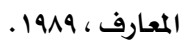

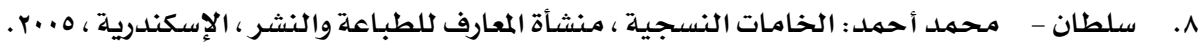

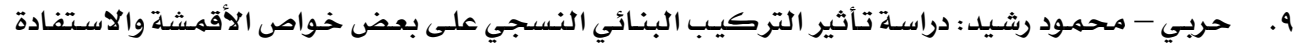

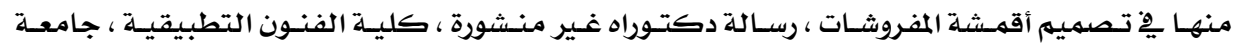
حلوان ، 1910. (190.

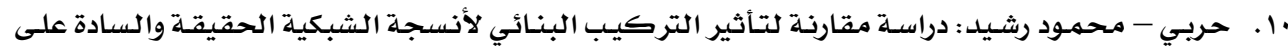

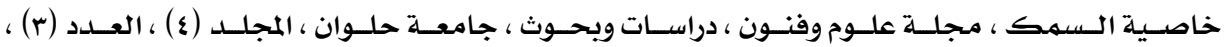

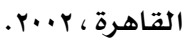

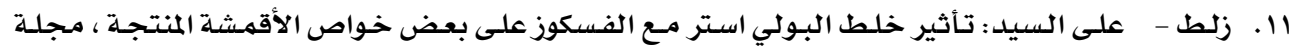

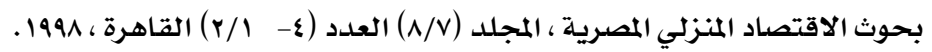

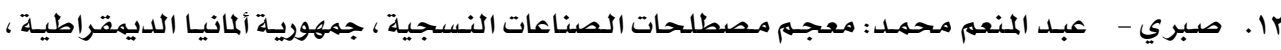
ليبزج ، 19V0. rا. عامر - حامد عبد الرعوف: إمكانية تحديد أنسب المعايير القياسية لمراقبة جودة أقمشة الملابس الصيفية

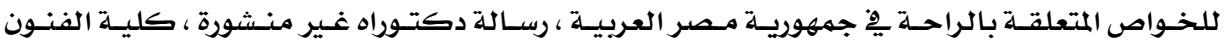

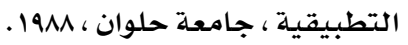

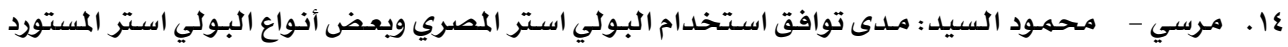

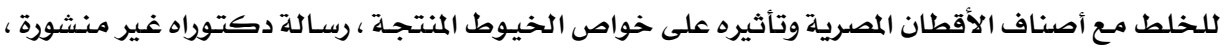

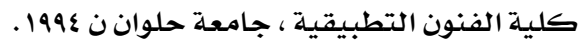




\section{ثانيا: المراجع الأجنبية}

15. Booth, J.E., "Textile mathematics, the textile institute, Manchester, U.K., 2008.

16. El-Gamal, M. A., Design of thermo-physical methodology for investigating the comfort properties of working clothing, $\mathrm{PhD}$ thesis, engineering Dep., Moscow textile Uni., 1982.

17. Green wood, ., Weaving, control of fabric structure, Marrow publishers. U.K., 2010.

18. Grosicki, Z. J., Watson's textile design and color, 7th edition, U.K., 2006.

19. Kozlowski, R. M.: Fabrics influence on human physiological state, Marrow, U.K., 2002.

20. Lord, P. R., \& Mohamed, M. H., Weaving: Conversion of Yarn to Fabric, Marrow, U.K., 2000.

21. Morton \& Hearse J. W. S., Physical properties of textile fibers. U.K., 2005.

22. Watkins, Suzan, Clothing: The portable environment, First edition, the Lowe State Uni., Press, 1984. 


\section{Determining the best structural criteria for evaluating the thermal properties flowing outer-wear.}

\section{Abstract}

Since flowing outer-wear occupies an important value in Egypt and other Arab countries, this paper emphasized on investigating their thermal properties. The main target of this research, is to determine the more effective structural factors, in relation to the thermal properties of the flowing outer-wear, in the climatic circumstance of hot countries.

Fiber content, weave structure, clothing density, yarn density, fabric thickness, porosity and fabric weight were tested. PPMCC statistical method was used for analyses the research results. Polyester blended with Nylon, Woven with plain weaves showed inferior thermal properties. Pure polyester fabrics woven with sateen structure have the best thermal properties for flowing outer clothes. 